NBER WORKING PAPER SERIES

\title{
EFFICIENCY AND EQUITY IMPACTS OF URBAN TRANSPORTATION POLICIES WITH EQUILIBRIUM SORTING
}

\author{
Panle Jia Barwick \\ Shanjun Li \\ Andrew R. Waxman \\ Jing $\mathrm{Wu}$ \\ Tianli Xia \\ Working Paper 29012 \\ http://www.nber.org/papers/w29012 \\ NATIONAL BUREAU OF ECONOMIC RESEARCH \\ 1050 Massachusetts Avenue \\ Cambridge, MA 02138
}

July 2021, Revised February 2022

We thank Kelly Bishop, Jan Brueckner, Shengmao Cao, Gilles Duranton, Fernando Ferreira, Edward Glaeser, Matthew Kahn, Robert Metcalfe, Alvin Murphy, Matías Navarro, Stuart Rosenthal, Kerry Smith, Christopher Timmins, and seminar participants at Boston University, Brazilian School of Economics and Finance, Cornell, Duke, Jinan University, MIT, Peking University, Shanghai University of Finance and Economics, University of Illinois, University of Maryland, University of Texas - Austin, University of Wisconsin - Madison, the World Bank, the 2019 Urban Economics Association meeting, and the 2021 NBER Summer Institute for helpful comments. We acknowledge the excellent research assistance from Avralt-Od Purevjav and Ziye Zhang and financial support from the International Initiative for Impact Evaluation (3ie) under project DPW1.1106 and from the Center for Transportation, Environment, and Community Health at Cornell University. The views expressed herein are those of the authors and do not necessarily reflect the views of the National Bureau of Economic Research.

NBER working papers are circulated for discussion and comment purposes. They have not been peer-reviewed or been subject to the review by the NBER Board of Directors that accompanies official NBER publications.

(C) 2021 by Panle Jia Barwick, Shanjun Li, Andrew R. Waxman, Jing Wu, and Tianli Xia. All rights reserved. Short sections of text, not to exceed two paragraphs, may be quoted without explicit permission provided that full credit, including $\odot$ notice, is given to the source. 
Efficiency and Equity Impacts of Urban Transportation Policies with Equilibrium Sorting Panle Jia Barwick, Shanjun Li, Andrew R. Waxman, Jing Wu, and Tianli Xia

NBER Working Paper No. 29012

July 2021, Revised February 2022

JEL No. H23,R3,R41,R48,R51

\begin{abstract}
We estimate an equilibrium sorting model of housing location and commuting mode choice with endogenous traffic congestion to evaluate the efficiency and equity impacts of a menu of urban transportation policies. Leveraging fine-scale data from household travel diaries and housing transaction data identifying residents' home and work locations in Beijing, we recover structural estimates with rich preference heterogeneity over both travel mode and residential location decisions. Counterfactual simulations demonstrate that even when different policies reduce congestion to the same degree, their impacts on residential sorting and social welfare differ drastically. First, driving restrictions create large distortions in travel choices and are welfare reducing. Second, distance-based congestion pricing reduces the spatial separation between residences and workplaces and improves welfare for all households when it is accompanied by revenue recycling. Third, sorting undermines the congestion reduction under driving restrictions and subway expansion but strengthens it under congestion pricing. Fourth, the combination of congestion pricing and subway expansion delivers the greatest congestion relief and efficiency gains. It can also be self-financed, with the cost of subway expansion fully covered by congestion pricing revenue. Finally, eliminating preference heterogeneity, household sorting, or endogenous congestion significantly biases the welfare estimates and changes the relative welfare rankings of the policies.
\end{abstract}

Panle Jia Barwick

Department of Economics

Cornell University

462 Uris Hall

Ithaca, NY 14853

and NBER

panle.barwick@cornell.edu

Shanjun Li

Cornell University

405 Warren Hall

Ithaca, NY 14853

and NBER

SL2448@ cornell.edu

Andrew R. Waxman

University of Texas at Austin

awaxman@utexas.edu
Jing Wu

Department of Construction Management

and Hang Lung Center for Real Estate

Tsinghua University

China

ireswujing@tsinghua.edu.cn

Tianli Xia

tx58@cornell.edu 


\section{Introduction}

Transportation plays a crucial role in shaping the urban spatial structure and the organization of economic activity. In many developing countries, rapid urbanization and motorization, together with poor infrastructure, have created unprecedented traffic congestion with severe economic consequences (Davis, 2008; Li, 2018; Akbar et al., 2018; Gu et al., 2020). ${ }^{1}$ To address these challenges, local governments around the world have implemented a suite of policies, including driving restrictions, public transit investment, congestion pricing, and gasoline taxes. In the short term, the effectiveness of these policies in alleviating congestion crucially hinges on the substitutability of travel modes and the sensitivity of travel demand to changes in commuting costs. In the medium to long run, these policies are likely to have broader impacts on the urban spatial structure through households adjustment of residential locations. This adjustment, in turn, could mediate the effectiveness of transportation policies on congestion reduction. In addition, many policies that address congestion have distributional consequences. For example, collecting tolls could intensify equity considerations since low-income households spend a larger share of their income on transportation. This paper aims to understand the efficiency and equity impacts of urban transportation policies while accounting for multiple adjustment channels and equilibrium effects. To do so, we jointly model residential locations and travel mode choices in an equilibrium sorting framework with endogenous congestion.

The empirical context of our study is Beijing, which has a population of 21.5 million and has routinely been ranked one of the most congested and polluted cities in the world. Beijing's municipal government has implemented several policies to aggressively combat traffic congestion and air pollution. It has adopted a driving restriction policy since 2008 that restricts vehicles from driving one weekday per week based on the last digit of the license plate. It also invested a staggering $\$ 100$ billion in transportation infrastructure between 2007 and 2018 by adding 16 new subway lines with a total length of $523 \mathrm{~km}$. Beijing's anticongestion policies (driving restrictions and subway expansion) together with a proposed congestion pricing scheme represent three general approaches to regulating the unpriced congestion externality-the first a command-and-control, the second a supply-side, and the third a demand-side approach.

Exploiting this policy-rich context, we first develop a stylized theoretical model based on LeRoy and Sonstelie (1983) and Brueckner (2007) to account for endogenous congestion and heterogeneity in income and commuting technologies. The model highlights the countervailing forces at play in travel mode and housing location choices and illustrates both the efficiency and the distributional consequences of transportation policies. Our reduced-form evidence corroborates the theoretical predictions that driving restrictions steepen the bid-rent curve and lead to a higher premium for properties in desirable locations (e.g., close to subway

\footnotetext{
${ }^{1}$ The TomTom Traffic Index, based on real-time GPS traffic data from 403 cities in 56 countries, shows that the ten most congested cities in 2018 were all from developing and emerging economies. The top five cities were Mumbai, Bogota, Lima, New Delhi, and Moscow. Drivers in Mumbai spent 65\% more commuting time on average than they would have under the free-flow condition. Los Angeles, the most congested city in the US, was ranked $24^{\text {th }}$ with a congestion index of $41 \%$. Four cities in China (including Beijing) were among the top 30 on the list. Beijing's drivers spend nearly 180 extra hours on the road (or 9\% of working hours) per year relative to the travel time under the free-flow speed due to traffic congestion. The full ranking based on the TomTom Traffic Index 2018 is available at https://www.tomtom.com/en_gb/traffic-index/ranking.
} 
stations). Motivated by the theoretical predictions and reduced-form evidence, we then build and estimate an equilibrium model of residential sorting with endogenous congestion that incorporates preference heterogeneity and allows general equilibrium feedback between housing locations and commuting decisions through congestion. In the model, households choose a residence, and conditional on their home location, they also choose travel modes for commutes. A key consideration in a household's choice of a residential property is the associated ease of commute for working members of the household. The utility derived from an easier commute is an equilibrium object that crucially depends on congestion, which varies across locations and is determined by all households' travel choices and residential locations. Once estimated, the model allows us to conduct counterfactual simulations to predict new equilibrium outcomes under different policies in terms of travel mode choices, household locations, the congestion level, housing prices, and welfare distribution.

Our structural analysis leverages data at fine spatial resolution from two unique sources that allow us to jointly model residential locations and commuting choices. The first is the Beijing Household Travel Survey (BHTS) from 2010 and 2014, a large representative survey that records households' home and work locations, trips made in a 24-hour window, and other demographic and transportation-related information. We complement this dataset by constructing all feasible home-to-work commuting choices with historical geographical information system (GIS) maps and the application programming interface (API) from online mapping services. This exercise allows us to compile the commuting route, distance, travel time and pecuniary travel cost for each trip-mode combination (walking, biking, bus, subway, car, or taxi). The second dataset contains housing transactions from a major government-run mortgage program and provides a large representative sample of Beijing home buyers. Critically for our analysis, the housing data report not only the home but also the work locations of both the primary and secondary borrowers. Using this information, we construct over 13 million hypothetical work-commute and travel-mode combinations for all primary and second borrowers with the same GIS and API procedure used for the travel survey data. To our knowledge, these datasets constitute the most comprehensive data on work-commute travel and housing transactions ever used in the context of equilibrium sorting models.

We use a two-step strategy to estimate the equilibrium sorting model. The first step recovers heterogeneous preferences on travel times and monetary costs (and thereby the value of time) using information on the time and pecuniary cost for both the chosen travel mode that is reported in the household travel surveys and alternative modes that we constructed using various GIS and APIs. We then utilize the estimated parameters from this step and the work locations of both the primary and secondary borrower (which primarily correspond to husband and wife in our setting) to construct the ease-of-commute attribute separately for each commuter in the household and for all properties in a household's choice set. These variables are included as household property-specific attributes in the housing demand estimation below.

The second step of our estimation procedure recovers preferences for housing attributes from observed home purchases. The key estimation challenge arises from the potential correlation between unobserved housing attributes and the housing price as well as the ease-of-commute utility, where the latter two variables are equilibrium outcomes. To address this challenge, we construct three sets of instrumental variables (IVs) 
in the spirit of Berry et al. (1995) and Bayer et al. (2007). These IVs include the number of houses sold in a two-month window around the sales date within a reasonable distance from a given property. We also use as IVs the average housing and neighborhood attributes for these properties and the time-varying odds of winning a license lottery to purchase a vehicle. The first and second sets of IVs proxy for the extent of competition faced by a given property (the number and attributes of alternative properties on the market). The third set of IVs reflects exogenous policy-induced shifts in demand for houses in premium locations, such as places close to subways or in the city center. We account for a rich set of observed and unobserved preference heterogeneity and estimate parameters through maximum likelihood estimation with a nested contraction mapping combined with the IV approach (Train and Winston, 2007).

Our results confirm the importance for both the travel mode and residential location decisions of preference heterogeneity, which significantly improves model fit. The average and median value of time (VOT) from our preferred specification is $95.6 \%$ and $84.6 \%$ of survey respondents' hourly wage, consistent with estimates in recent literature. In addition, the ease-of-commute attributes substantially improve the ability to explain observed housing choices. A noteworthy result of the estimation is that households are willing to pay $18 \%$ more for similar reductions in a wife's than in a husband's commuting time. Our structural model provides the first estimates of the income elasticity of housing demand and the income elasticity of the marginal commuting cost in one unified framework. These elasticities are key determinants of the urban spatial patterns of residential locations.

Utilizing these estimates, we then simulate equilibrium residential sorting and transportation outcomes based on three policies of interest in our study: driving restrictions, subway expansion, and congestion pricing, as well as combinations of the three. We decompose the welfare effect along five margins. The first channel measures changes in welfare when households change travel mode in response to increasing commuting costs, holding congestion and residential locations fixed. The second and third channels separately consider partial speed adjustments that are common to the empirical transportation literature. The first adjustment does not clear the transportation sector, while the second is a full equilibrium speed adjustment that clears the transportation sector. The fourth channel incorporates sorting and simulates general equilibrium outcomes with changes in both congestion and residential locations. Lastly, we model housing supply adjustments. We are unaware of any prior work in the urban economics literature that combines a structurally estimated model with simulations to decompose all of these margins of adjustment.

Our policy simulations yield four key findings. First, while all three policies are designed to reduce congestion, they exhibit different and sometimes opposite impacts on the spatial patterns of residential locations and equilibrium housing prices. The congestion alleviation under the driving restriction disproportionately benefits long commutes and leads to minimal sorting. In contrast, distance-based congestion pricing provides strong incentives for commuters in both the high- and low-income groups to move closer to their workplaces. In comparison, subway expansion generates the most variable changes in commuting costs across households. The sorting responses from subway expansion are also the opposite of what occurs under congestion pricing. Subway expansion disperses households away from the city center into the suburbs and locations near new 
subway stations.

Second, different transportation policies can either exacerbate or alleviate economic inequality (Waxman, 2017; Tsivanidis, 2019; Akbar, 2020). High-income households' welfare is greater under congestion pricing (in the absence of revenue recycling), and low-income households' welfare is greater under subway expansion. Without revenue recycling, congestion pricing is regressive, creating a significant impediment to its adoption in practice. With appropriate revenue recycling, low-income households can also be better off under congestion pricing than in the no-policy scenario.

Third, residential sorting can either strengthen or undermine the congestion-reduction potential of transportation policies. Sorting enhances the efficacy of congestion pricing for congestion relief because households, especially those with long commutes, are incentivized to live closer to their work locations and drive less. This magnifies the welfare gain of congestion pricing by as much as $40 \%$ for high-income households and $16 \%$ for low-income households. On the other hand, sorting in response to subway expansion leads to a further separation between residential and work locations, dampening the congestion-reduction effect and welfare gains from infrastructure investment.

Finally, transportation policies generate different aggregate welfare implications. Beijing's rapid subway expansion increased consumer surplus and aggregate welfare despite the fact that it has achieved only a modest congestion reduction. In contrast, driving restrictions are welfare reducing in spite of their larger associated congestion reduction. Congestion pricing and subway expansion in tandem deliver the largest improvement to traffic speed and net welfare gain-equivalent to $3 \%$ of average household income. In addition, the revenue from congestion pricing could fully finance the capital and operating costs of subway expansion, eliminating the need to resort to distortionary taxes. These results showcase the strengths of our sorting model in capturing various adjustment margins and evaluating different policy scenarios under a unified framework that accounts for general equilibrium effects and preference heterogeneity.

We conduct several extensions and robustness checks, considering housing supply variation, ring roadspecific traffic density, migration, and consumption access, as well as the removal of random coefficients. Housing supply fluctuations in response to housing price changes allow more people to move to desirable locations and magnify the role of sorting. Our results are similar with region-specific traffic density. Shutting down random coefficients grossly underestimates the benefit of subway expansion and overestimates the welfare loss from driving restrictions and congestion pricing. Incorporating migration and consumption access considerations does not change the qualitative results of our analysis.

Our study makes three main contributions. First, it adds to the literature on equilibrium sorting. Sorting models have been used to study consumer preferences for local public goods and urban amenities (e.g., air quality, school quality, and open space) and evaluate policies that address economic, social and environmental challenges (Epple and Sieg, 1999; Bayer et al., 2007; Kuminoff et al., 2013). ${ }^{2}$ Most existing papers treat both

\footnotetext{
${ }^{2}$ See, for example, Ferreyra (2007) and Epple et al. (2012) on school quality; Sieg et al. (2004), Bayer et al. (2009), Kuminoff (2009), and Bayer et al. (2016) on air quality; Timmins and Murdock (2007), Walsh et al. (2007), and Klaiber and Phaneuf (2010) on open space and recreation; Bajari and Kahn (2005), Bayer et al. (2007), Bayer and McMillan (2012), and Hwang (2019) on racial and ethnic composition; Calder-Wang (2020) on the distributional impacts of the sharing economy in the housing market; Almagro and
} 
the distance to work and the level of congestion as exogenous attributes. An attempt to address this limitation is made in Kuminoff (2012), which models household decisions in both the work and housing markets and endogenizes the commuting distance but keeps congestion exogenous. Our paper is, to our knowledge, the first in the empirical equilibrium sorting literature to explicitly model household residential locations and travel mode choices jointly and evaluate how these choices simultaneously determine both congestion and distance to work in equilibrium. We show that the aggregate welfare implications qualitatively differ based on whether we account for or abstract from endogenous changes in congestion.

Second, our study relates to the recent advances using quantitative spatial equilibrium (QSE) models to explore the role of transportation in urban systems (see Redding and Rossi-Hansberg (2017) for a review). There has been a limited attempt in this literature to examine the role of preference heterogeneity and endogenous congestion in mediating the welfare effects of transportation policies. Our framework accounts for rich heterogeneity in observed and unobserved preferences by leveraging detailed household-level data instead of relying on more tractable distributional assumptions (i.e., Fréchet) and limited differentiation (such as heterogeneity in educational attainment) as the QSE models do. ${ }^{3}$ Incorporating such preference heterogeneity matters for evaluating equilibrium responses to transportation policies: removing unobserved preference heterogeneity results in welfare estimates that are both qualitatively and quantitatively different. Some recent QSE studies (Allen and Arkolakis, 2019; Fajgelbaum and Schaal, 2020) explicitly model endogenous congestion with an increasing marginal external cost (Anderson, 2014). Unlike these studies, our work estimates the VOT and congestion costs based on individual-level commuting decisions from large travel surveys.

Third, our paper bridges a gap in the literature examining short- and long-run responses to transportation policies. ${ }^{4}$ While most studies in this literature focus on short-run effects on travel choices, traffic congestion, and air pollution, some studies examine longer-run partial equilibrium effects and find substantially different results (e.g., Duranton and Turner (2011)). As pointed out by Gallego et al. (2013), little has been done to understand the set of adjustments that happen in the transition from the short to the medium or long run. Understanding these adjustments is crucial from a policy perspective since municipalities often need to plan for infrastructure provision and address development concerns over the medium run. By characterizing the underlying travel and housing choices, our equilibrium sorting framework provides a microfoundation for linking the results between short- and long-run reduced-form impact evaluation studies. More importantly, the unified framework offers a common yardstick to compare actual and counterfactual policies over a range of outcomes

Domínguez-Iino (2020) and Couture et al. (2020) on endogenous amenities across neighborhoods, and Ferreira and Wong (2021) on recovering neighborhood preferences with imperfect information.

${ }^{3}$ An important exception is Couture et al. (2020), who examine the welfare effects of US urbanization in a quantitative spatial model that allows significant heterogeneity. However, the model abstracts from the general equilibrium effects in housing and transportation markets at play in this paper.

${ }^{4}$ Various policies have been evaluated. See Parry and Small (2005), Bento et al. (2009), and Li et al. (2014) on gasoline taxes; Bento et al. (2005), Parry and Small (2009), Duranton and Turner (2011), Anderson (2014), Basso and Silva (2014), Li et al. (2019), Severen (2019), and Gu et al. (2020) on public transit subsidies and expansion; Davis (2008), Viard and Fu (2015), Zhang et al. (2017), and Jerch et al. (2021) on driving restrictions; and Langer and Winston (2008), Anas and Lindsey (2011), Hall (2018), Yang et al. (2020), and Kreindler (2018) on congestion pricing. 
including congestion reduction, urban spatial structure, social welfare, and distributional consequences. ${ }^{5}$

The paper proceeds as follows. Section 2 describes the data and policy background. Section 3 sets up the theoretical framework and provides reduced-form evidence on how Beijing's driving restrictions affect the housing market. The reduced-form evidence motivates and grounds the subsequent structural analysis. Section 4 lays out the equilibrium sorting model and the estimation strategy. The estimation results are presented in Section 5. Section 6 explains the counterfactual simulation algorithm. Section 7 examines different transportation policies and compares their welfare consequences. Section 8 concludes.

\section{Policy Background and Data Description}

\subsection{Policy Background}

The central and municipal governments in China have pursued a series of policies to address growing urban traffic congestion over the past decades. In Beijing, these policies include a driving restriction scheme, vehicle purchase restrictions, and an investment boom in subway and rail transportation infrastructure. The driving restrictions were implemented as part of Beijing's effort to prepare for the 2008 Summer Olympics. ${ }^{6}$ Initially, half of all vehicles were restricted from driving on a given weekday based on their license plate name. After the Olympics concluded, the restrictions were relaxed to apply to each car on only one weekday per week depending on the last digit of the plate. Acquiring a second vehicle to avoid the restriction is difficult since in 2011, Beijing also put in place a binding quota system that caps the number of new vehicle sales in an attempt to curb the growth in vehicle ownership. Winning a car license in this lottery became increasingly difficult over time: the odds of winning decreased from 1:10 in early 2012 to nearly 1:2,000 in 2018, as the pool of lottery participants increased while the number of licenses fell over time (Xiao et al., 2017; Li, 2018; Liu et al., 2020). ${ }^{7}$ These time-series changes in the odds of winning provide useful exogenous variation for the housing demand analysis, as we discuss below.

Beyond implementing these demand-side policies, the Beijing municipal government also invested heavily in public transportation infrastructure. From 2007 to 2018, 16 new subway lines were built with a combined length of over $500 \mathrm{~km}$ (See Appendix Figure A1 for subway maps over time). By the end of 2019, Beijing had the world's longest and busiest subway system, with a total length of nearly $700 \mathrm{~km}$ and daily ridership of over 10 million. This expansion echoed the boom in infrastructure investment across many regions in China. The number of cities with a subway system in mainland China increased from four to over 40 from 2000 to

\footnotetext{
${ }^{5}$ Another approach in the literature allows feedback effects between the transportation sector and housing market in a calibrated computable general equilibrium framework without estimating the underlying consumer preferences (Anas and Kim, 1996; Langer and Winston, 2008; Parry and Small, 2009; Basso and Silva, 2014). Compared with the approach in these studies, our framework is internally consistent in that the estimation of the structural parameters and policy simulations are based on the same model.

${ }^{6}$ Athens, Greece, implemented the first driving restrictions in 1982. Since then, a dozen other large cities in the world, including Bogotá, Mexico City and New Delhi, have adopted similar policies. The impacts of these policies on congestion and air pollution have been mixed (Davis, 2008; Viard and Fu, 2015; Zhang et al., 2017).

${ }^{7}$ About 20,000 new licenses were distributed each month through nontransferable lotteries from 2011 to 2013. The monthly quota was reduced to 12,000 after 2013. These quotas were set considerably lower than the historical vehicle sales in Beijing.
} 
2019 , and the total urban rail network reached over $6,700 \mathrm{~km}$ by the end of 2019 . These expansions were designed, in part, to slow the growth of personal vehicle use by making public transportation more accessible. (See Anderson (2014); Yang et al. (2018); Gu et al. (2020) for a recent analysis on the impact of subway expansion on traffic congestion.)

Despite these policy efforts, traffic congestion continues to be a pressing issue: the average traffic speed in 2019 was $24.6 \mathrm{~km} / \mathrm{h}$ during peak hours (7-9 am and 5-7 pm), according to the 2020 Beijing Transportation Report. From a neoclassical microeconomic perspective, the aforementioned policies fail to directly address the root cause of traffic congestion: the mispricing of road capacity. ${ }^{8}$

\subsection{Data Description}

We rely on two main datasets for our analysis: a) the Beijing Household Travel Surveys from 2010 and 2014 and b) housing mortgage data from 2006-2014 with detailed information on household demographics and the work addresses of home buyers. Appendix Section A provides more detail on the data construction.

Beijing's Geography Beijing's spatial structure is characterized by high population density at the center, with a set of concentric ring roads encircling the city center. The second ring road largely traces the city limits of pre-1980s Beijing, from which the city has subsequently expanded outward. We focus on the geographical areas within the sixth ring road, which approximately separates the city proper from its suburbs. Appendix Figures A2 and A3 map out the city contour and various ring roads, commercial centers (with a greater density of job opportunities), subway lines, districts, and amenities including signature elementary schools and parks.

Beijing is not perfectly monocentric. There are several large work clusters across the city, such as the financial cluster between the second and fourth ring roads on the east side of the city and a high-tech cluster toward the northwest between the third and fifth ring roads. The city has 65 signature schools designated by the municipal government as the key elementary schools. These schools have better resources and better student performance. Signature schools are concentrated within the fourth ring road, while parks are more dispersed across the city.

Beijing has a total of 18 districts, each containing on average eight jiedao (neighborhoods). A jiedao is an administrative unit, similar to a census tract, where homes share similar observed and unobserved amenities. The average size of a jiedao is 15.7 square $\mathrm{km}$. For transportation planning purposes, Beijing is also divided into roughly 2,000 traffic analysis zones (TAZs), which are standardized spatial units based on residential and employment density. TAZs are one square kilometer on average and smaller when they are closer to the center of Beijing. Most of the maps in this paper use TAZs as the spatial unit.

\footnotetext{
${ }^{8}$ Despite being continuously advocated by economists since Vickrey (1963), adoption of congestion pricing has been limited in practice largely due to technical feasibility and especially political acceptability. During the last 15 years, several European cities (London, Milan, Stockholm, and Gothenburg) have successfully implemented various congestion pricing schemes. After considering several proposals, the New York state legislature recently approved a congestion pricing plan for New York City, which-pending approval of the scheme by the Federal Highway Administration-is set to become the first US city to enact congestion pricing.
} 
Beijing Household Travel Survey We utilize two rounds of the Beijing Household Travel Survey (BHTS) collected in 2010 and 2014 by the Beijing Transportation Research Center (BTRC), an agency of the Beijing municipal government. The survey is designed to inform transportation policies and urban planning. It includes data on individual and household demographics (e.g., income, household size, vehicle ownership, home ownership, age, gender) and occupations, availability of transportation options (vehicles, bikes, etc.), and a travel diary on all trips taken during the preceding 24 hours. This trip information includes the origin and destination, departure and arrival time, trip purpose and travel mode used.

Our analysis focuses on 73,154 work commuting trips (home-to-work and work-to-home). Work trips account for the majority of the total travel distance and time: they constituted $62 \%$ and $75 \%$ of the total travel distance and 53\% and 59\% of the weekday trips among working-age respondents in 2010 and 2014, respectively. Table 1 provides summary statistics for variables used in the analysis by survey year. Household income increased dramatically from 2010 to 2014, with the share of the lowest income group (less than $¥ 50,000$ annually) decreasing from $48 \%$ to $18 \%$. The proportion of households owning vehicles increased from $44 \%$ to $62 \%$. The share of respondents living and the share of those working within the fourth ring road (which proxies for the city center) both decreased by about 10 percentage points from 2010 to 2014, reflecting the increased spatial dispersion of housing and work locations.

To understand commuters' travel mode choices, we construct attributes for all travel modes in their choice set. We focus on six travel modes: walk, bike, bus, subway, car, and taxi, as other modes (motorcycles, company shuttles, and unlicensed taxis) collectively account for less than $4 \%$ of all trips. Appendix Figures A4 and A5 illustrate the procedures used to calculate the mode-specific travel time and monetary cost. We use the Baidu API to calculate the travel time and distance for walking, biking, car and taxi trips. Baidu Maps incorporates the predicted congestion level based on the time of day and day of week in its estimated trip duration. We query the Baidu API at the same departure time as that recorded in the travel survey (e.g., 7 am) to capture within-day variation in congestion (i.e., at peak vs. off-peak hours). To account for changes in the average congestion between the survey year and the year that we query the Baidu API, we adjust the predicted driving, taxi, and bus travel times based on the historical traffic congestion index (e.g., a 10\% difference in the traffic congestion index is associated with a $10 \%$ adjustment of the travel time). The driving speed is the ratio of the travel distance to the travel time.

We use the Gaode Map API to calculate the travel time by bus because Gaode reports the number of transfers and walking time between bus stops and delivers more accurate estimates. To take into account the subway expansion occurring during our sample period, we use historical subway maps and GIS software to reconstruct the historical subway network. The subway travel time is calculated based on the published time schedules of subway lines. Our calculation assumes that commuters use the subway stations closest to their trip origin and destination and incorporates the walking distance and walking time to the subway stations in the total trip distance and duration. We validate these constructed trip-mode attributes (e.g., duration) with information from reported trips in the travel survey.

Figure 1 plots for each travel mode the observed share of commuting trips and the constructed travel time, 
cost, and distance. Panel (a) contrasts the travel patterns in 2010 with those in 2014 and presents several notable changes. First, walking accounts for a significant share of all commuting trips: $15.0 \%$ and $13.5 \%$ in 2010 and 2014, respectively. These trips take 51 and 40 minutes on average with a distance of 4.9 and $3.7 \mathrm{~km}$. Second, from 2010 to 2014, the shares of walk, bike, and especially bus trips decreased while the shares of car (i.e., driving) and subway trips increased, reflecting rising vehicle ownership and expansion of the subway network. Third, walking and subway trips are the longest in duration, while subway and car trips are the longest in distance. Car trips have a slightly longer duration and distance than taxi trips but are cheaper. Overall, the trade-off between time and cost is clear: walking trips are the slowest but also the cheapest. Car and taxi trips are faster but more expensive than other trip types.

Panel (b) of Figure 1 contrasts travel patterns between high- and low-income (above- and below-median income) households. High-income households are more likely to drive, use the subway, and take taxis and are less likely to use other travel modes. As a percentage of the hourly wage, car and taxi trips are much more expensive for low-income than for high-income households. There is little difference in travel distance across the two income groups except for the distance of car trips. This echoes evidence from the housing data below that there is limited income-delineated residential sorting.

Housing Transactions The data on housing transactions come from a major government-sponsored mortgage program in Beijing and cover July 2006 to July 2014. As is reflective of the housing supply in urban China, most housing units are within housing complexes, equivalent to condominiums in the US. Virtually all eligible home buyers apply for mortgages through this program before obtaining commercial loans, as it offers a subsidized interest rate that is more than $30 \%$ lower than commercial mortgage rates. Each transaction in our data corresponds to a mortgage, and there are no refinancing loans in the sample.

The final dataset includes 77,696 mortgage transactions, with detailed information on housing attributes such as the property size, age, and street address, the transaction price, and then date when the mortgage was signed. ${ }^{9}$ We also observe household demographic details including income, age, marital status, residency status (hukou), and - critically for our analysis - the work addresses of the primary borrower and the coborrower if one is present. We geocode the home and work addresses to their latitude and longitude and construct measures of proximate amenities (e.g., schools and parks). The mortgage data represent a subset of housing transactions (not all buyers apply for mortgages) and may be subject to selection issues. To address this concern, we reweight the mortgage data to match the distribution of housing price, size, age, and distance to the city center among all housing transactions from a separate dataset by using entropy balancing (Hainmueller, 2012). All of the empirical analyses use the weighted sample. The results estimated with the unweighted sample are robust. Appendix Section A.2 discusses the reweighting procedure in more detail and describes additional data patterns, such as differences in commuting distance by gender.

Table 2 provides summary statistics of the data. Figure 2 shows the spatial pattern of housing and house-

\footnotetext{
${ }^{9}$ We remove transactions with a missing or zero reported price, a price lower than $¥ 5,000 / \mathrm{m}^{2}$ (the average price is $¥ 19,800 / \mathrm{m}^{2}$ ), buyers with no reported income, and addresses outside the sixth ring road.
} 
hold attributes based on mortgage transactions from 2006 to 2014, with a warmer color representing a higher value. Housing prices tend to be higher and the distance to work shorter near the city center. The outskirts of Beijing have larger homes with a lower unit price, reflecting the classic distance-housing size trade-off illustrated in the monocentric city model in Section 3. There are also exceptions. For example, the high-tech center in northwestern Beijing outside the fifth ring road has high housing prices and short commutes that are comparable to those corresponding to places in the city center. The northern parts of the city have higher-quality amenities (schools and parks) and more work opportunities and attract high-income households. While household income is generally higher in northern Beijing than in southern neighborhoods, households of different income levels tend to mix together throughout most parts of the city.

Our equilibrium sorting model examines households' residential choices. In theory, a home buyer's choice set could potentially consist of all properties listed on the market, and researchers need to construct hypothetical commuting attributes of different travel modes for all properties in a buyer's choice set. However, this is technically infeasible because the number of potential home-work-mode combinations exceeds hundreds of billions. This issue of large choice sets is a common empirical challenge in the housing demand literature. To reduce the computational burden, we follow a choice-based sampling strategy. ${ }^{10}$. The choice set for a household is assumed to include the purchased home and a $1 \%$ sample of houses randomly chosen from those sold during a two-month window around the purchase date. Beijing's real estate market was fluid during our sample period. The median number of days on the market was only 8 and 13 in 2013 and 2014, respectively, with the average in the same years being 22 and 38 days. Section 5 conducts robustness analyses using different choice sets and finds little impact on our estimates. For each property in a household's choice set, we construct the travel mode attributes for both the primary borrower's and coborrower's work commute, based on their respective work locations. The construction of the travel mode attributes involves over 13 million route-mode combinations.

Auxiliary Dataset To estimate the relationship between traffic density and speed, we use the same traffic data as Yang et al. (2020). The data contain real-time traffic volume and speed data at 30-minute intervals from over 1,500 remote traffic microwave sensors covering all major roads throughout Beijing for 2014.

\section{Theoretical Framework and Reduced-Form Evidence}

\subsection{Theoretical Framework}

We motivate our setup with a graphical presentation of two of the transportation policies examined in our empirical analysis: congestion pricing and driving restrictions. These policies affect both the transportation sector (the primary market) and also the housing market (the secondary market) through sorting.

\footnotetext{
${ }^{10}$ Choice-based sampling for differentiated demand has been demonstrated to yield consistent results in Wasi and Keane (2012) and Guevara and Ben-Akiva (2013)
} 
Figure 3 illustrates the welfare effects in the primary market for vehicle road traffic. The economic cost induced by congestion is the difference between the marginal social cost $(M S C)$ and marginal private cost $(M P C)$. Both congestion pricing and driving restrictions result in a reduction of the traffic volume from the unregulated level, $V^{0}$, to the socially optimal level, $V^{*}$. However, there are crucial differences between the two schemes. Congestion pricing reduces the trips with the lowest marginal benefit and leads to welfare gains (the shaded red area). Driving restrictions, as a command-and-control approach, eliminate trips at all levels of marginal benefit. The blue triangle in Figure 3 represents the welfare loss associated with the quantity restriction. Its size is positively related to the degree of heterogeneity in the marginal benefit of trips. As a result, the welfare impact of the driving restrictions is ambiguous.

Figure 3 is only a partial equilibrium analysis and does not take into account the impact of transportation policies on the housing market. It also abstracts from differences across households. To understand these additional effects, we extend the classical monocentric models of land use in LeRoy and Sonstelie (1983) and Brueckner (1987) by incorporating income heterogeneity, multiple transportation technologies, and endogenous congestion, which are important elements in our empirical model. Households with different incomes sort into different locations in response to transportation policies based on their preferences for housing, other goods and time. Appendix Section B presents the model details and the theoretical predictions.

The model predicts that both the driving restriction and the congestion pricing schemes steepen the bidrent curve and lead to a higher premium on proximity to the central business district (i.e., workplace) but that subway expansion yields the opposite effect. In addition, driving restrictions are more likely than congestion pricing to push rich households to move closer to their workplaces, as driving restrictions impose higher costs on rich households. Subway expansion disperses both groups to the city suburbs. The model highlights that while the transportation policies' primary effect on commuting costs is straightforward, their secondary effect on the spatial distribution of households and housing price capitalization can be large and depends on relative differences in the marginal cost of commuting, income heterogeneity, and preferences for housing size and travel time. While illustrative, the theoretical model ignores a host of important features, such as the polycentricity of most cities, travel modes beyond car and subway trips, household attributes other than income, and variation in the availability of housing across the city. For these reasons, we turn to an empirical equilibrium sorting model to evaluate different policies.

\subsection{Reduced-Form Evidence}

Before proceeding to the structural model, we present reduced-form evidence for the capitalization of transportation policies into housing prices. Specifically, we examine the housing market response to the car driving restriction (CDR) policy that began in July 2008. Figure 4 shows scatter plots of housing prices in $¥ 1,000 / \mathrm{m}^{2}$ against the distance to the nearest subway station before and after the CDR. ${ }^{11}$ The top panel uses raw data,

\footnotetext{
${ }^{11}$ We focus on two years before and after the starting date of the program to balance the trade-off between sample size and potential confounding changes in the housing market and transportation sector. We remove observations from July to September 2008 . The policy was more aggressive in July-September 2008, when half of all vehicles were subject to the restriction on any given weekday
} 
while the bottom panel shows residualized plots after we include year-by-month and neighborhood fixed effects. The price gradient becomes steeper post-CDR, suggesting that homes close to subways command a higher price premium under the policy: being one kilometer closer to subway increases a house's price premium by about $¥ 100 / \mathrm{m}^{2}$ (about $1 \%$ of the housing price). Consistent with theoretical predictions, the driving restrictions increase the price premium of homes near subway stations. Appendix Table A1 reports regression results for various specifications, suggesting a very similar impact magnitude even after we include richer controls such as complex attributes, city district-by-year fixed effects, and subway density to better account for time-varying amenities.

Appendix Section C provides an event-study analysis and a falsification test, lending additional support to the finding. In addition, we specify a piecewise linear function of price on subway distance to allow the price gradient to vary by distance band. The results suggest a convex price function, where the marginal impact of subway proximity is the strongest for properties within $5 \mathrm{~km}$ but tapers off after $10 \mathrm{~km}$. The relationship between subway proximity and housing price is strengthened under the policy, especially for properties between 5 and $10 \mathrm{~km}$ away.

The reduced-form analysis above confirms the importance of housing market capitalization and the presence of sorting in response to transportation policies. To compare the impacts of different transportation policies and to quantify the underlying mechanisms and margins of adjustment (changes in commuting modes vs. changes in residential locations), we now turn to an equilibrium sorting model that features preference heterogeneity and endogenous congestion.

\section{Empirical Equilibrium Sorting Model}

The sorting model characterizes individual commuting choices and residential location decisions. It also specifies the joint equilibrium conditions for the transportation sector and the housing market. On the one hand, residential locations determine households' commute distances and affect driving demand and hence traffic congestion. On the other hand, traffic congestion affects the attractiveness of different residential locations and consequently housing demand. For example, high congestion levels increase demand for premium locations (places close to subways and the city center). The equilibrium nature of our sorting model allows counterfactual simulations and provides direct comparative statics of congestion levels, residential locations, housing prices, and social welfare across different policies.

The model assumes that work locations are determined ex ante and examines housing choices given work locations. In practice, these decisions could be made either simultaneously or sequentially. Our assumption is motivated by three observations. First, for many households, the choice of work location is likely to be the outcome of a longer-term process of labor supply and migration decisions. ${ }^{12}$ Second, employment opportu-

(due to the 2008 Olympics in August), and was relaxed to a restriction on driving during one weekday per week for each car from October 2008.

${ }^{12}$ The annual rate of job switching among formal-sector employees in Beijing was about 4\% per year from 2006 to 2014 . About $60 \%$ of home buyers in our data started a new job within the three years prior to purchasing the home. 
nities in the same industry tend to be clustered in Beijing. Hence, switching jobs may not entail meaningful changes in work locations. Third, while the mortgage data provide rich information on housing locations and current employment, they do not report the alternative job opportunities available to each household. In addition, adding the labor market component would significantly complicate our empirical analysis given the rich individual-level observed and unobserved preference heterogeneity incorporated into our model.

Our approach contrasts with the emerging literature that uses QSE models to evaluate transportation policies incorporating the joint processes of work and residential location decisions. Unlike that literature, the current work cannot analyze whether changes in the transportation system translate to higher labor productivity (e.g., through better allocation of time and labor market matching), which is a limitation of our approach. ${ }^{13}$ On the other hand, our approach has several advantages. First, QSE models use observed worker flows and wages to recover iceberg commuting costs via gravity equations and origin-destination-specific (dis)amenities. Recent studies (Allen and Arkolakis, 2019; Fajgelbaum and Schaal, 2020) allow endogenous congestion but still rely on gravity equations to describe commuting flows. In contrast, we estimate preferences over commuting time and monetary costs and hence the VOT directly through observed individual commuting choices and explicitly model the externality of endogenous congestion. This is important as VOT is the single most important parameter for the welfare effects of transportation policies. ${ }^{14}$ Second, in contrast to the flexible and rich observed and unobserved preference heterogeneity in our setting, unobserved preference heterogeneity in QSE models is often limited to Fréchet draws for analytic tractability, with homothetic preferences for ease of aggregation. ${ }^{15}$ The ability to flexibly specify heterogeneous preferences (which are nonhomothetic) has important welfare implications, as we document in Section 7 below.

\subsection{Housing Demand}

We specify a characteristic-based housing demand model, where preferences over housing units are parameterized as a function of both observed and unobserved property attributes and household characteristics (Lancaster, 1971; Berry et al., 1995). Our data are longitudinal, but we suppress time $t$ to ease exposition. Variables in bold denote vectors. Conditioning on work locations, the utility for household $i$ choosing housing

\footnotetext{
${ }^{13}$ In addition, our analysis does not model agglomeration forces. Diamond (2016) is a microfounded study that bridges this gap by incorporating housing and labor markets into the evaluation of the heterogeneous welfare consequences of worker movements between US cities, although it does not endogenize congestion from the transportation sector. We also abstract from dynamic considerations. For recent papers with dynamic models on the housing market, see Almagro and Domínguez-Iino (2020); Han et al. (2018); Murphy (2015); Wang (2020).

${ }^{14}$ As Ken Small has written in Small (2012), "It is difficult to name a concept more widely used in transportation analysis than the value of travel time. Its theoretical meaning and its empirical measurement are fundamental to travel demand modeling, social cost analysis, pricing decisions, project evaluation, and the evaluation of many public policies."

${ }^{15}$ Welfare improvements in QSE models usually result from changes in real income due to gains from trade via an increase in market access. This benefit is directly mediated through import elasticity with respect to variable trade costs (Arkolakis et al., 2012). In the context of urban transportation, this approach seems potentially limiting because spatial mismatch and wasteful commuting due to preexisting distortions, like congestion, may leave open opportunities for Pareto improvements without a change in the level of market access.
} 
unit $j$ is specified as:

$$
\max _{\left\{j \in J_{i}\right\}} U_{i j}=\alpha_{i} p_{j}+\mathbf{x}_{j} \beta_{i}+\sum_{k} \phi_{i k} E V_{i j k}\left(v_{i j k}\right)+\xi_{j}+\varepsilon_{i j}
$$

where $J_{i}$ is the choice set for household $i, p_{j}$ denotes the home price, and $\mathbf{x}_{j}$ denotes a vector of observed housing attributes such as the size and number of bedrooms. Household members with commuting needs are denoted by $k \in\{$ Primary borrower, Coborrower $\} . E V_{i j k}\left(v_{i j k}\right)$ is the expected commuting utility for member $k$ in household $i$ derived from the optimal commuting mode. It characterizes home $j$ 's attractiveness in terms of member $k$ 's work commute. Our notation makes it explicit that the commuting utility depends on the driving speed $v_{i j k}$ in member $k$ 's work commute (which is affected by congestion) in addition to the travel time and cost. As shown in Section 4.2, this commuting utility is our key innovation relative to traditional residential sorting models. In our setup, transportation policies can generate differential impacts on the commuting utility of housing units through a variety of channels: households' heterogeneous commuting preferences, changes in households' commuting modes, and endogenous congestion (which affects the driving speed) as a result of the policy. The variable $\xi_{j}$ represents unobserved housing attributes, and $\varepsilon_{i j}$ is an i.i.d. error term with the type I extreme value distribution that reflects unobserved preferences over each housing choice.

The household-specific price coefficient $\alpha_{i}$ is related to the log of household income $y_{i}$ :

$$
\alpha_{i}=\alpha_{1}+\alpha_{2} * \ln \left(y_{i}\right)
$$

Household preferences over housing attributes are denoted as $\beta_{i}$, which consists of a household-specific component and a population average. For each element $\mathrm{s}$ in $\beta_{i}$ :

$$
\beta_{i s}=\bar{\beta}_{s}+\mathbf{z}_{i} \beta_{s}
$$

where $\mathbf{z}_{i}$ is household demographics such as age and income. The ease-of-commute preference $\phi_{i k}$ differs across household members and is characterized by random coefficients:

$$
\phi_{i k}=\bar{\phi}_{k}+\phi_{k} \zeta_{i k}, k \in\{\text { Primary borrower, Co-borrower }\} \text {, }
$$

where $\zeta_{i k}$ is i.i.d. normal. In subsequent formulations, we suppress subscript $k$ for ease of exposition and use $E V_{i j}$ to denote the commuting utility for both household members $\sum_{k} \phi_{i k} E V_{i j k}$.

The probability that household $i$ chooses home $j$ is denoted by:

$$
P_{i j}(\mathbf{p}, \mathbf{v})=h\left(\mathbf{E V}(\mathbf{v}), \mathbf{p}, \mathbf{X}, \boldsymbol{\xi}, \mathbf{z}_{i}\right)
$$

where $\mathbf{p}$ and $\mathbf{v}$ denote prices and driving speed and $\mathbf{E V}(\mathbf{v})$ is a vector of the ease-of-commute utility for different properties given household $i$ 's work locations. The triplet $\mathbf{X}, \boldsymbol{\xi}$, and $\mathbf{z}_{i}$ denotes observed housing 
attributes, unobserved housing quality, and household $i$ 's demographics, respectively.

\subsection{Choice of Travel Mode}

Utility-maximizing individuals within a household choose from six commuting modes (walk, bike, bus, subway, car, and taxi) based on the trip time and financial cost of each. The travel survey reports travel mode choices for each commuting member of a household. ${ }^{16}$ With slight abuse of notation, we use $i$ to denote an individual within a household rather than the whole household in this subsection. Individual $i$ 's utility of commuting from home $j$ to work using mode choice $m$ is specified as:

$$
\max _{m \in M_{i j}} u_{i j m}=\theta_{i m}+\gamma_{1 i} \cdot \operatorname{time}_{i j m}\left(v_{i j}\right)+\gamma_{2} \cdot \operatorname{cost}_{i j m} / y_{i}+\mathbf{w}_{i j m} \eta+\varepsilon_{i j m},
$$

where $M_{i j}$ is the set of transportation modes available to individual $i$ commuting from home $j$. Variable $t i m e_{i j m}$ denotes the commute duration between $i$ 's work location and home $j$ via mode $m$. The driving time for trips with the commuter's own vehicle or taxis $\left(t_{i m e} e_{i j, c a r}\right.$ and $\left.t i m e_{i j, t a x i}\right)$ depends on the driving speed $v_{i j}$, which is ultimately determined by the congestion level. ${ }^{17}$ The monetary cost of the trip is denoted as cost $_{i j m}$ and household income as $y_{i}$. The variable $\mathbf{w}_{i j m}$ includes mode-commuter-specific controls (such as the driving dummy interacted with commuter's gender) and time and spatial fixed effects. Finally, $\varepsilon_{i j m}$ is the i.i.d. error term with the type I extreme value distribution.

We allow a mode-specific random coefficient, $\theta_{i m}$, that has a normal distribution with mean $\mu_{m}$ and variance $\sigma_{m}$. Without loss of generality, the random coefficient for walking is normalized to zero. These random coefficients capture heterogeneous preferences that vary across individuals, such as the enjoyment of driving a car, the perceived environmental friendliness of using public transportation, scheduling or inconvenience costs that vary across individuals but do not scale with the time or distance traveled, and the health benefits of biking and walking. The time preference $\gamma_{1 i}$ follows a chi-squared distribution with three degrees of freedom and mean $\mu_{\gamma}$. The chi-squared distribution allows all individuals to have a positive value of time. An individual's sensitivity to the monetary costs of commuting is assumed to decrease in income: $\gamma_{2} / y_{i}$.

Our utility specification makes it straightforward to calculate the VOT, which is $\frac{\gamma_{1 i}}{\gamma_{2}} \cdot y_{i}$. This measure scales with income by linking the valuation of time to the hourly wage. The VOT is the most important preference parameter for transportation decisions (Small, 2012). Small et al. (2005) demonstrate the importance of modeling rich preference heterogeneity to recover accurate VOT estimates and evaluate transportation policies. Section 5 illustrates that our estimates accurately reflect the preferences of Beijing commuters.

\footnotetext{
${ }^{16}$ We treat the mode choices of different individuals within a household as independent, as we do not observe whether and how mode choices within households are determined. We also abstract from trip-chaining, which is unlikely to be of first-order importance for home buyers.

${ }^{17}$ Road congestion affects the travel time for bus trips in addition to car and taxi trips. However, this effect is more complicated as it depends on the local design of the roadway, structure of bus schedules, and locations of bus stops. For the purpose of our analysis, we treat buses as if they run in dedicated lanes unaffected by congestion, which may result in an overprediction of bus mode shares in simulations with higher congestion levels.
} 
Conditional on home location $j$, the probability that individual $i$ chooses mode $m$ for his or her work commute is defined as:

$$
R_{i j m}\left(v_{i j}\right)=r\left(\operatorname{cost}_{i j} / y_{i}, \mathbf{t i m e}_{i j}\left(v_{i j}\right), \mathbf{w}_{i j m}\right)
$$

where $\operatorname{cost}_{i j} / y_{i}$ and time ${ }_{i j}\left(v_{i j}\right)$ denote the vector of travel cost (as a share of individual $i$ 's hourly wage) and travel time from home $j$ to $i$ 's work location for all travel modes, respectively. The vector $\mathbf{w}_{i j m}$ captures all other individual- and trip mode-specific characteristics.

The ex ante expected commuting utility (before the realization of travel shocks) is defined as:

$$
E V_{i j}\left(v_{i j}\right)=\mathbb{E}_{\varepsilon_{i j m}}\left(\max _{m \in M_{i j}} u_{i j m}\left(v_{i j}\right)\right)
$$

where the expectation is over the set of i.i.d. draws $\varepsilon_{i j m}$ across travel modes.

\subsection{Market-Clearing Conditions and the Sorting Equilibrium}

The equilibrium market-clearing conditions for the housing market and the transportation sector are interrelated in our model. In the housing market, choices of individual households aggregate to total housing demand, and housing prices adjust to equate demand and supply. In the transportation sector, the equilibrium congestion level and hence driving speed is jointly determined by driving demand through all individuals' travel mode choices and road capacity. These two markets interact in two dimensions: The spatial locations of households affect the distance of work commutes and the choice of travel mode and hence congestion and driving speeds in the transportation sector. At the same time, the level of traffic congestion that is determined in the transportation sector affects the attractiveness of residential locations through the commuting utility as discussed above, which, in turn, shapes the spatial distribution of households. We discuss these market-clearing conditions below.

Housing Market The aggregation of households' choice probabilities $P_{i j}$ gives rise to the housing demand:

$$
D_{j}(\mathbf{p}, \mathbf{v})=\sum_{i} P_{i j}(\mathbf{p}, \mathbf{v}), \forall j
$$

Housing demand depends on both housing prices $\mathbf{p}$ and the driving speed $\mathbf{v}$ (through the ease-of-commute utility). We consider two scenarios for housing supply. In the first scenario, housing supply is fixed at one for all properties: $S_{j}(\mathbf{p})=1$ (the supply for each property unit is one). In the second scenario, housing supply has a constant elasticity, $\ln \left(S_{j}\right)=c_{j, 0}+\mathfrak{e} * \ln \left(p_{j}\right)$, and increases $\mathfrak{e} \%$ with a $1 \%$ increase in the housing price.

Transportation Sector Demand for driving is determined by both housing locations and travel mode choices. Intuitively, mode choices determine the extensive margin (the decision on whether to drive), while housing locations determine the intensive margin (the commuting distance). Total driving demand and hence traffic density in region $s$ is the aggregation of the location and commuting decisions for relevant households, which 
ultimately depends on the housing price $\mathbf{p}$ and driving speed $\mathbf{v}$ :

$$
D_{s}^{v}(\mathbf{p}, \mathbf{v}) \equiv \sum_{i \in s} \sum_{j} P_{i j}(\mathbf{p}, \mathbf{v}) \cdot\left\{\left[R_{i j, c a r}(\mathbf{v}) \cdot \operatorname{dist}_{i j, c a r}\right]+\left[R_{i j, t a x i}(\mathbf{v}) \cdot \operatorname{dist}_{i j, t a x i}\right]\right\}
$$

where $P_{i j}$ is the probability that household $i$ chooses location $j, R_{i j, c a r}$ and $R_{i j, t a x i}$ are the probabilities that household $i$ living in location $j$ drives and takes taxi, respectively, and dist ${ }_{i j, c a r}$ and dist ${ }_{i j, t a x i}$ are the commuting distance by car and taxi.

The appropriate choice of region $s$ is context specific and defines the geographical scope of congestion's negative externality. Our main analysis assumes that the scope of congestion is city-wide, but we also consider extensions where the traffic density is ring-road specific (i.e., it differs for the regions between the second and third ring roads, between the third and fourth ring roads, etc.). ${ }^{18}$

The supply side of the transportation sector describes the relationship between the traffic density $S^{v}$ (the number of vehicles on the road) and the travel speed $\mathbf{v}$ that can be sustained given Beijing's existing road capacity. We assume the density and speed relationship has a constant elasticity:

$$
\ln \left(S^{v}(\mathbf{v})\right)=c_{0}+\mathfrak{e}^{v} * \ln (\mathbf{v})
$$

For a $1 \%$ increase in traffic speed, the traffic density that can be sustained under the existing road capacity goes down by $\left|\mathfrak{e}^{\mathfrak{v}}\right| \%$. This supply relationship helps to determine the extent of the congestion externality: other drivers on the road reduce household $i$ 's driving speed. Figure 3 depicts the congestion externality and illustrates how the equilibrium congestion level is determined under driving restrictions and congestion pricing.

Sorting Equilibrium A sorting equilibrium is defined as a vector of housing prices, $\mathbf{p}^{*}$, and a vector of driving speed, $\mathbf{v}^{*}$, such that

1. The housing market clears for all properties:

$$
D_{j}=\sum_{i} P_{i j}\left(\mathbf{p}^{*}, \mathbf{v}^{*}\right)=S_{j}\left(\mathbf{p}^{*}\right), \forall j
$$

2. The transportation sector clears for every region $s$, where households' aggregate driving demand at speed $\mathbf{v}^{*}$ is equal to the traffic density that can be sustained under the existing road capacity at speed $\mathbf{v}^{*}$ :

$$
D_{s}^{v}\left(\mathbf{p}^{*}, \mathbf{v}^{*}\right)=S_{s}^{v}\left(\mathbf{v}^{*}\right), \forall s
$$

Our model follows the class of equilibrium sorting models with local spillovers studied in Bayer and

\footnotetext{
${ }^{18}$ The use of a single speed adjustment factor to reflect congestion is consistent with theoretical work modeling congestion spillovers in dense downtown intersections like water rising in a bathtub (Arnott, 2013).
} 
Timmins (2005) and more closely in Bayer et al. (2007), where the local spillover in our context is traffic congestion from personal vehicles. If the error terms in both the housing demand equation (1) and commuting mode choice equation (3) are from continuous distributions (such as the type I extreme value distribution), then the equation system (2), (4), (7), and (8) is continuous. The existence of a sorting equilibrium follows Brouwer's fixed point theorem. Intuitively, a unique vector of housing prices (up to a scalable constant) $\mathbf{p}^{*}$ solves the system of equations defined by equations (2) and (7), conditional on a set of observed and unobserved housing attributes ( $\mathbf{X}$ and $\boldsymbol{\xi}$ ) and the traffic speed $\mathbf{v}$. At the same time, equations (4) and (8) define a continuous mapping of traffic speed $\mathbf{v}$ on a compact and convex set. The fixed point of the equation system (2), (4), (7), and (8) defines the equilibrium housing prices and traffic speed $\left\{\mathbf{p}^{*}, \mathbf{v}^{*}\right\} .{ }^{19}$

\subsection{Estimation Details}

This subsection discusses how we estimate the parameters that characterize housing demand, the travel mode choice, and the traffic density-speed relationship. We estimate the housing demand separately from the travel mode choice using two separate data sets. Appendix Section D includes further details. Following the vast literature on discrete choice models, we assume that the error terms in both the housing demand equation (1) and the commuting mode choice equation (3) have type I extreme value distribution.

Estimation of Travel Mode Choices The parameters of the travel mode choices are estimated via simulated maximum likelihood estimation (MLE) using the household travel surveys. The key parameters of interest are the time and monetary cost preferences. We include mode-specific random coefficients to capture (dis)amenities that do not scale with the time or distance traveled. We also interact mode-specific fixed effects with year fixed effects, district fixed effects, and demographic variables (such as commuters' income and age). These interactions control for a rich set of time-varying and location-specific unobservables by travel mode.

We assume that the error term $\varepsilon_{i j m}$ in equation (3) is uncorrelated with commuting trips' time and monetary costs. This assumption would be violated if, for example, the route-specific quality of public transit service (i.e., in terms of congestion, delay, comfort, or safety) is correlated with route-specific monetary costs or travel time. Monetary costs are likely to be exogenous because Beijing's transportation bureau sets bus and subway fares uniformly across all routes. Hence, fares do not vary by the level of congestion or quality of service. Travel time is determined by congestion. We include a rich set of mode, time, and spatial fixed effects to absorb shocks that are common across households and affect both travel speed and the error term $\varepsilon_{i j m}$. The remaining variation in $\varepsilon_{i j m}$ reflects idiosyncratic considerations that are unlikely to be correlated

\footnotetext{
${ }^{19}$ The proof of equilibrium existence closely follows Bayer and Timmins (2005) and is available upon request. In our model with spatially varying congestion responses and preference heterogeneity for endogenous attributes, uniqueness is not guaranteed. One sufficient condition for a unique equilibrium requires exogenous attributes of housing and commuting to be "sufficiently explanatory" of demand relative to endogenous ones, as pointed out by Bayer et al. (2004). To address the possibility of multiple equilibria, we simulate our model with 100 different initial starting values. The simulation analyses always converge to the same equilibrium outcomes, providing empirical evidence for uniqueness in our applied setting. Our practice follows the recent literature (such as Couture et al. 2020; Hwang 2019) that incorporates rich preference heterogeneity and multiple margins of adjustment to maintain realism without imposing restrictions to guarantee a unique equilibrium outcome.
} 
with travel time.

Once we have estimated parameters from travel mode choices, we plug them in the housing transaction data and construct the ease-of-commute utility $E V_{i j}$ by equation (5), which takes the usual log-sum formula for errors with the type I extreme value distribution. A key underlying assumption of this 'plug-in' approach is that after we account for location and demographic differences, commuters' preferences as estimated from travel surveys are representative of the commuting preferences of home buyers in the mortgage data. Note that the calculation of $E V_{i j}$ is computationally intensive and requires us to construct the travel time and cost for all available travel modes for every property in households' choice sets, as described in Section 2.2.

Choice Set of the Housing Demand Computational and data limitations often require restrictions on the number of alternatives in demand estimation. While it may be logical to restrict households' choice set to a set of affordable or nearby homes, Banzhaf and Smith (2007) shows that this approach may bias estimation due to unobserved heterogeneity in the choice set definition. Instead of restricting the choice set based on attributes, we rely on choice-based sampling methods, which have been proven to deliver consistent estimates in multinomial logit and mixed logit models by Wasi and Keane (2012) and Guevara and Ben-Akiva (2013). We take a $1 \%$ random sample of the houses sold during a two-month window around the purchase date of the chosen home. The average size of a choice set is 27 . A robustness check using a $0.5 \%$ random sample yields very similar results (Section 5.2).

Estimation of Residential Location The estimated $E V_{i j}$ in the previous stage enters the housing demand equation (1) as an observed housing attribute. Similar approaches that nest the expected utility as a choice attribute have been used by Capps et al. (2003) and Phaneuf et al. (2008) to estimate healthcare and recreational demand, respectively, though the application to residential sorting is new, to the best of our knowledge.

The parameters in the housing demand equation are estimated using a two-step procedure: the first step uses simulated MLE with a nested contraction mapping, and the second step uses the linear IV. The two-step strategy follows the approach of Berry et al. (1995) and Bayer et al. (2007) to address the challenge related to the presence of endogenous variables in nonlinear estimations (namely, that unobserved housing attributes $\xi_{j}$ render the price variable endogenous and bias the price coefficient toward zero). In the first step, we search for preference parameters to maximize simulated MLE while inverting the population-average utilities $\delta_{j}$ (also called the alternative-specific utility; see equation (11) below) by using a nested contraction mapping algorithm. In the second step, we regress the population-average utilities $\delta_{j}$ on prices instrumented by IVs to recover unbiased estimates of the price coefficients.

Specifically, we reorganize household $i$ 's utility of purchasing property $j$ into a sum of household-specific 
utility $\mu_{i j}$ and population-average utility $\delta_{j}$ (which absorbs the unobserved housing attribute $\xi_{j}$ ):

$$
\begin{aligned}
U_{i j} & =\mu_{i j}\left(\theta_{1}\right)+\delta_{j}\left(\theta_{2}\right)+\varepsilon_{i j} \\
\mu_{i j}\left(\theta_{1}\right) & =\alpha_{2} \ln \left(y_{i}\right) p_{j}+\mathbf{x}_{j} \mathbf{z}_{i} \beta+\sum_{k} \phi_{i k} E V_{i j k} \\
\delta_{j}\left(\theta_{2}\right) & =\alpha_{1} p_{j}+\mathbf{x}_{j} \bar{\beta}+\xi_{j} .
\end{aligned}
$$

where $k$ denotes each commuting member of household $i$. Note that we use $\theta_{1}$ to denote the parameters in equation (10) and $\theta_{2}$ to denote the parameters in equation (11). Appendix D provides further details about the estimation procedure.

Once $\theta_{1}$ are estimated and $\left\{\delta_{j}\right\}_{j}$ inverted from the observed data, we estimate equation (11) using three sets of IVs. The first is the number of properties a) within $3 \mathrm{~km}$ of property $j, \mathrm{~b}$ ) outside the same complex, and c) sold within a two-month window of property $j$ 's purchase date. ${ }^{20}$ This variable is arguably exogenous and correlated with housing price $p_{j}$ because the availability of desirable properties in close proximity exerts downward pressure on $p_{j}$ through competition. The second set of IVs is the average attributes of these properties (including their neighborhood attributes), which are also proxies for competition in the housing market. The third set of IVs includes the interaction between the second set of IVs and the odds of winning the license lottery discussed in Section 2.1. These odds decreased dramatically from 9.4\% in January 2011 to $0.7 \%$ by the end of 2014 . The interaction terms capture the likely impact of the license lottery on the nature of housing market competition and price setting. Decreasing winning odds push up demand (and hence prices) for properties in desirable locations, such as places close to the subway or city center.

Estimation of Speed-Density Elasticity We estimate the supply side of the transportation sector with the following equation:

$$
\ln \left(v_{s t}\right)=e^{v} * \ln \left(d_{s t}\right)+\mathbf{X}_{s t} \beta+\varepsilon_{s t},
$$

where the unit of observation is road segment by hour, $\ln \left(v_{j t}\right)$ is $\log$ speed in $\mathrm{km} / \mathrm{h}, \ln \left(d_{j t}\right)$ is the $\log$ of traffic density, measured by the number of vehicles per lane-km, and $e_{s}^{v}$ is the speed-density elasticity. The vector of $X_{j t}$ includes weather-related variables (temperature, wind speed, etc.) and time and spatial fixed effects (hourof-day, day-of-week, road segment, etc.). The key regressor $\ln \left(d_{s t}\right)$ could be correlated with the residual due to accidents, road construction, or major events. To address the potential endogeneity of traffic density, we construct IVs based on Beijing's driving restriction policy following Yang et al. (2020). The policy has a preset, rotating schedule that restricts each vehicle from driving one weekday per week based on the last digit of the license plate number. We construct a policy indicator taking 1 for the days when vehicles with a license number ending in 4 or 9 are restricted from driving. The policy generates exogenous variation in traffic density, as far fewer vehicles have license numbers ending in the digit 4 due to superstition.

\footnotetext{
${ }^{20}$ Alternative cutoffs, such as 1 or $5 \mathrm{~km}$, deliver similar results.
} 


\section{Estimation Results}

We discuss the estimation results on travel mode choices, housing demand, and the speed-density relationship, in turn, below.

\subsection{Commuting Mode Choice}

Table 3 presents parameter estimates for six specifications. The first three specifications do not have random coefficients. The only source of household heterogeneity comes from household income (and the interaction between travel costs and income). The last three specifications include random coefficients on travel time to capture unobserved consumer heterogeneity and random coefficients on travel modes. The VOT is defined by the ratio of the (random) coefficient on travel time and the parameter on travel costs. It is measured as a percentage of a household's hourly wage.

Column (1) controls for interactions between the year dummies (2010 or 2014) and mode fixed effects (car, taxi, bus, subway, walking, and biking). The implied VOT is $75.7 \%$ of the hourly wage. Column (2) adds the interactions between mode fixed effects and trip characteristics, including trip distance bins and trip origin and destination attributes (e.g., whether the trip origin is within the second ring road). These controls account for important features of travel demand and significantly improve the model fit. For example, the transportation literature has documented that drivers value the reliability of travel time (Brownstone and Small, 2005; Small et al., 2005). Uncertainty in travel time likely scales with the distance of a trip and is partially absorbed by the mode and trip-distance bin fixed effects. Ring road dummies for trip origins and destinations capture differences in the frequency and quality of public transit services. Column (3) further includes interactions of mode fixed effects with household demographic variables including age, gender, education, vehicle ownership, number of workers, and household size. These variables help explain different mode choices across demographic groups (e.g., wealthier households' greater likelihood of driving and using taxis) and further improves the model fit.

Columns (4) to (6) use a chi-squared distribution with three degrees of freedom to approximate heterogeneous travel time preferences following Petrin (2002). ${ }^{21}$ In addition to the random coefficient on travel time, Column (5) incorporates a random coefficient on the mode of driving. Column (6) further includes random coefficients for all travel modes (with walking as the reference group), capturing the impact of unobserved demographics on mode choices. For example, some commuters choose driving or taxiing not because of a high VOT but rather because of scheduling constraints. Others choose walking or biking for the exercise benefits. The dispersion of these preference parameters is economically large and statistically significant, suggesting significant preference heterogeneity.

The results of our preferred specification are in Column (6). Adding travel time and mode-specific random coefficients leads to a strong sensitivity to travel costs and delivers a much more reasonable estimate of the

\footnotetext{
${ }^{21}$ Following Petrin (2002), we winsorize the top and bottom 5\% of the distribution to minimize the impact of extreme random draws, as the VOT is unlikely to be infinite. The distribution with three degrees of freedom provides the best fit.
} 
VOT. Appendix Figure A6 depicts the VOT estimate histogram. The average and median VOT is $95.6 \%$ and $84.6 \%$ of the hourly wage, respectively, which is within the range typically found in the recent literature. ${ }^{22}$

We construct the commuting utility $\left(E V_{i j}\right)$ as defined in equation (5) for both male and female borrowers based on their work locations. ${ }^{23}$ These variables are included as part of the (buyer-specific) housing attributes in Section 5.2.

\subsection{Housing Location Choice}

We now turn to the estimation results of housing demand. We first present the MLE estimates of householdspecific preference parameters and then discuss the IV estimates for coefficients in the mean utility.

Table 4 reports three specifications: without the EV terms (the ease-of-commute utility), with the EV terms, and with random coefficients on the EV terms. The coefficient estimates are similar across specifications. As expected, high-income households tend to be less price sensitive. ${ }^{24}$ We interact the age group dummies with the distance to the nearest signature elementary school. Enrollment in these top schools is restricted to residents in the corresponding school district, and houses in these districts command a high premium. The baseline group is primary borrowers younger than age 30 . The interaction coefficients in all specifications are negative and highly significant, though borrowers between ages 30 and 45 exhibit the strongest preference for proximity to key schools, as they are the most likely to have school-age children.

We do not observe the household size. To capture preference heterogeneity in home sizes due to variation in the household size, we use the age of the primary borrower as a proxy and interact age group dummies with the property size. Older households have a stronger preference for large houses. The group over 45 has the strongest large-house preference, probably due to the presence of both children and elderly grandparents in the same household, a common household structure in China.

The EV terms for both household members have significant explanatory power and are associated with a sizeable increase in the log-likelihood. Both working family members prefer homes with easier commutes. To evaluate households’ willingness to pay (WTP) for a one-minute shorter commute (or for ¥1 savings in commuting costs), we search for changes in housing prices that would keep households' utility constant. Since we use housing transaction prices instead of rental prices in housing demand (equation (1)), the WTP

\footnotetext{
${ }^{22}$ In the context of travel demand, the VOT estimates typically range between $30 \%$ and $100 \%$ of hourly income (Small et al., 2007). Using a discrete choice framework similar to ours, Small et al. (2005) estimate the median VOT at $93 \%$ of the hourly wage for commuters in Los Angeles. Buchholz et al. (2020) use the trade-off between wait time and price among users on a large ride-hailing platform in Prague and find the average VOT to be roughly 100\% of users' wage during work hours. Goldszmidt et al. (2020) find an average (median) VOT of 75\% (100\%) of the hourly (after-tax) wage based on a large-scale field experiment by Lyft in 13 US cities. The US Department of Transportation recommends using 50\% of the hourly income as the VOT for local personal trips (e.g., work commute and leisure but not business trips) to estimate the value of travel time savings for transportation projects (USDOT, 2015). Leveraging the trade-off between vehicle driving speed and gasoline usage, Wolff (2014) estimates the average VOT in eight rural locations in Washington state to be $50 \%$ of the hourly wage based on traffic speed data.

${ }^{23}$ Around $61 \%$ of the primary borrowers are male, with the remaining $39 \%$ female. We set $E V_{i j k}=0$ for unemployed family members and ignore their commuting needs in the house purchase decision.

${ }^{24}$ The price coefficient is $\alpha_{1}+\alpha_{2} * \ln \left(y_{i}\right)$. Since $\alpha_{1}$ is negative, a positive $\alpha_{2}$ means the absolute level of price sensitivity is lower for higher-income households.
} 
estimates reflect the monetized lifetime utility over the property tenure. According to our preferred specification (Columns (5) and (6)), an average household is willing to pay $¥ 18,500$ on a home to shorten the male member’s daily work commute by one minute and $¥ 18,000$ to save $¥ 1$ in the male member’s commute cost. ${ }^{25}$ Households are willing to pay $18 \%$ more for a similar reduction in their female member's commuting time and monetary cost, suggesting that households prioritize the female member's commute convenience in housing choices. This is consistent with descriptive evidence that women tend to live much closer to their work locations (Appendix Figure A7) and existing literature (Le Barbanchon et al., 2020). There exists significant preference heterogeneity among households: the interquartile willingness to pay for a one-minute shorter commute is between $¥ 4,510$ and 23,400 and $¥ 5,300$ and 33,800 for the male and female member, respectively.

Table 5 reports the coefficient estimates on the population-average utility (equation (11)), conditioning on the specification in Table 4 that allows for random coefficients on the commuting utility (the EV terms). Columns (1) and (2) use OLS, while Columns (3)-(6) are from IV regressions. All regressions include the interaction of the month-of-sample and district fixed effects to capture time-varying changes in market conditions and amenities that could vary across districts in Beijing. Columns (2)-(6) also include 158 neighborhood (jiedao) fixed effects to capture unobserved time-invariant neighborhood amenities. We use the three sets of IVs for housing prices that are discussed in Section 4.4: the number of homes within $3 \mathrm{~km}$ outside the sample complex sold in a two-month time window of a given home sale; the average attributes of these properties; and the interaction between the second set of IVs and the odds of winning the license lottery. The results of our preferred specification with all instruments appear in Column (6), with a first-stage F statistic of 14.22.

The price coefficient estimate is negative and statistically significant across all columns. The IV estimates are larger in magnitude than the OLS estimates, consistent with the finding in the demand literature that unobserved product attributes bias OLS estimates toward zero. The average price elasticities derived from the OLS estimates are of the wrong sign, as the population average price coefficient is not negative enough to offset the positive coefficient of the income-price interaction. The average elasticities from the IV estimates vary from -1.34 to -1.94 in Columns (4)-(6). The signs on the other coefficient estimates from the IV regressions in Columns (3)-(6) are all consistent with intuition. Households prefer larger properties and those closer to signature schools but dislike older buildings and places far from parks. ${ }^{26}$

Incorporating the commuting utility not only improves the model fit but also has implications for other parameter estimates, especially the price coefficient and price elasticity. Appendix Table A2 reports the results for the population-average utility from the regression without the $E V$ terms. Both the price coefficient and especially price elasticities are smaller in magnitude, consistent with the downward bias arising from omission of important attributes ( $E V$ terms). Timmins and Murdock (2007) find a 50\% downward bias in the estimation

\footnotetext{
${ }^{25}$ Our empirical analysis delivers two estimates of the marginal util per $¥$ : one based on the marginal utility of the housing price and one based the marginal utility of the commuting cost. Equating these two estimates implies 600 trips per year for the male borrower and 700 trips for the female borrower over a 30-year housing tenure. These implied trip numbers are high though not implausible.

${ }^{26}$ While the coefficient of distance to key schools is positive for the base group (borrowers under 30), the coefficient for borrowers between 30 and 45 is negative and significant, as the latter are more likely to have school-aged children.
} 
of consumer welfare from recreation sites when on-site congestion is ignored in demand estimation.

To examine the robustness of our results to the choice sampling method, we repeat the analysis with a $0.5 \%$ instead of $1 \%$ random sample to construct households' choice sets. The results are shown in Appendix Tables A3 and A4. The average price elasticity is -1.64 with the $0.5 \%$ random sample and -1.44 with the $1 \%$ random sample. The parameter estimates and implied willingness to pay for housing attributes are quite similar across these two samples.

Based on the parameter estimates from our preferred specification (the last set of results in Tables 4 and 5), the average income elasticity of housing size and the income elasticity of marginal driving costs are 0.10 and 0.78 , respectively. ${ }^{27}$ To our knowledge, these are the first estimates of these elasticities for Chinese households. Our estimated elasticity for housing size is somewhat smaller than estimates based on U.S. data, while the elasticity of marginal driving costs is largely consistent with other estimates in the literature. Using the 2003 American Housing Survey, Glaeser et al. (2008) find the elasticity of lot size to be from 0.25 to 0.5. They argue that these estimates provide an upper bound on the income elasticity of land demand. In comparison, our elasticity of housing demand is in terms of the (condo) interior size rather than the lot size.

\subsection{Speed-Density Elasticity}

To recover the speed-density elasticity (the supply side of the transportation sector), we use hourly data from remote traffic microwave sensors that cover all major roads throughout Beijing for 2014. We focus on observations with traffic density higher than 35 cars per lane-km (Column 5). The average speed of these observations is $30 \mathrm{~km} / \mathrm{h}$, close to the city-wide average speed during peak hours. The peak-hour speed is more relevant since we focus on commuting trips.

To examine potential differences in the speed-density elasticity across regions, we split our sample into four groups based on the location of traffic sensors: between the second and third ring roads, the third and fourth ring roads, the fourth and fifth ring roads, and the fifth and sixth ring roads. Appendix Table A5 reports the IV-estimated speed-density elasticity. The extent of heterogeneity among groups is limited, with the OLS and IV estimates comparable across columns. ${ }^{28}$ In the counterfactual analysis below, we use the city-wide speed-density elasticity estimate of -1.1 .

\section{Counterfactual Simulation Algorithm}

To evaluate Beijing's transportation policies, we examine five scenarios: driving restrictions, congestion pricing, subway expansion, and combinations of these policies. The first scenario follows the actual driving restriction scheme implemented in Beijing: a vehicle is prohibited from driving on one of the five work-

\footnotetext{
${ }^{27}$ To calculate these elasticities, we increase household income, re-solve the equilibrium for both the housing market and the transportation sector (holding housing supply fixed), and calculate the changes in housing size and driving costs.

${ }^{28}$ We do not report IV results for Column 4, the fifth to sixth ring road group, since driving restrictions are only implemented for roads within the fifth ring road.
} 
days. Under the congestion pricing scheme, which is hypothetical, we choose a distance-based charge (at $¥ 1.13 / \mathrm{km}$ ) to achieve the same level of congestion reduction as that resulting from the driving restriction policy to facilitate comparison. The subway expansion simulation compares the subway networks in 2008 and 2014. During this period, the length of the subway network increased from $100 \mathrm{~km}$ to $486 \mathrm{~km}$, with 8 additional lines in operation. We conduct the entire counterfactual analysis using the 2014 cohort to allow for maximum coverage of the subway expansion. Appendix E explains in detail the simulation algorithm. We provide a brief outline below. Readers not interested in this material can proceed to Section 7.

\subsection{Simulating the Counterfactual Equilibrium}

The counterfactual equilibrium is defined as new vectors of housing prices and travel speed $\left\{\mathbf{p}^{*}, \mathbf{v}^{*}\right\}$ that satisfy the market-clearing conditions (equations (7) and (8)). We iterate equations (7) and (8) sequentially to find the unique fixed point $\left\{\mathbf{p}^{*}, \mathbf{v}^{*}\right\}$.

The iteration process requires us to update the driving speed vector that can be sustained given the existing road capacity at new traffic density levels. To do so, we use the following formula:

$$
\frac{\tilde{v}_{i j}-v_{i j}^{o}}{v_{i j}^{o}}=e^{v} * \frac{\tilde{d}_{s}-d_{s}^{o}}{d_{s}^{o}},
$$

where $\tilde{v}_{i j}$ is the counterfactual driving speed for household $i$ 's work commute from home $j, v_{i j}^{o}$ is the observed driving speed (see Section 2.2 and Online Appendix A for its construction), and $\tilde{d}_{s}$ and $d_{s}^{o}$ are the counterfactual and observed traffic density for region $s$, respectively.

The size of region $s$ defines the geographical scope of the congestion externality. We consider two scenarios. In the first scenario, the scope of this externality is assumed to be city-wide. Hence, traffic density is measured by the aggregate driving demand of all Beijing households via equation (6): $d_{s}=d=$ $\sum_{i} \sum_{j} P_{i j} \cdot\left\{\left[R_{i j, c a r} \cdot\right.\right.$ dist $\left._{i j, c a r}\right]+\left[R_{i j, t a x i} \cdot\right.$ dist $\left.\left._{i j, t a x i}\right]\right\}$. We plug in the estimated speed-density elasticity $e^{v}=-1.1$ to update the counterfactual driving speed. Note that the driving speed $\tilde{v}_{i j}$ differs across households though the traffic density is city-wide. In the second scenario, we assume that the scope of the congestion externality is ring road specific. To accommodate this assumption, we construct the ring road-specific traffic density by allocating each household's drive commute to the appropriate ring road traffic density based on the trip origin and destination.

\subsection{Welfare Decomposition}

We now consider the underlying channels that govern welfare changes. Households' ex ante welfare is:

$$
W_{i}=\mathbb{E}_{\varepsilon_{i j}}\left(\max _{j \in J_{i}} U_{i j}(\mathbf{p}, \mathbf{v}, \mathbf{t})\right),
$$


where $\mathbf{p}, \mathbf{v}, \mathbf{t}$ are vectors of the housing price, travel speed, and commuting cost, respectively. Transportation policies directly affect commuting costs $\mathbf{t}$. The total derivative of household welfare with respect to commuting costs consists of five elements, corresponding to different margins of adjustment:

$$
\begin{aligned}
& \frac{d W}{d t}=\underbrace{\left.\frac{\partial W}{\partial t}\right|_{\mathbf{p}=\mathbf{p}_{0}, \mathbf{v}=\mathbf{v}_{0}}}_{\text {(1) direct policy effect }}+\underbrace{\left.\frac{\partial W}{\partial \mathbf{v}^{\prime}} \frac{\partial \mathbf{v}}{\partial t}\right|_{\tilde{\mathbf{v}}}}_{\text {(2) + (3) equil. speed effect }}+\underbrace{\left.\frac{\partial W}{\partial \mathbf{v}^{\prime}} \frac{\partial \mathbf{v}}{\partial t}\right|_{D^{v}\left(\mathbf{v}^{*}\right)=S^{v}\left(\mathbf{v}^{*}\right)}-\left.\frac{\partial W}{\partial \mathbf{v}^{\prime}} \frac{\partial \mathbf{v}}{\partial t}\right|_{\tilde{\mathbf{v}}}}_{\text {(2) rartial speed effect }} \\
& +\underbrace{\left.\frac{\partial W}{\partial \mathbf{p}^{\prime}} \frac{\partial \mathbf{p}}{\partial t}\right|_{D\left(\mathbf{p}^{*}, \mathbf{v}^{*}\right)=1}}_{\text {equil. (4) sorting effect }}+\underbrace{\left.\frac{\partial W}{\partial \mathbf{p}^{\prime}} \frac{\partial \mathbf{p}}{\partial t}\right|_{D\left(\mathbf{p}^{*}, \mathbf{v}^{*}\right)=S}-\left.\frac{\partial W}{\partial \mathbf{p}^{\prime}} \frac{\partial \mathbf{p}}{\partial t}\right|_{D\left(\mathbf{p}^{*}, \mathbf{v}^{*}\right)=1}}_{\text {(5) housing supply effect }} .
\end{aligned}
$$

The first channel, the direct policy effect, measures changes in household welfare when commuters change their travel mode in response to increasing commuting costs. The housing price, traffic speed, and household residential locations are fixed at their initial values. The second channel captures the partial speed effect, where the traffic speed adjusts one time from $\mathbf{v}^{0}$ to $\tilde{\mathbf{v}}$ via equation (13) as households reoptimize their travel mode choices, without imposition of the transportation sector's clearing condition. For example, the driving restriction moves $20 \%$ of drivers off the road, which leads to an initial $22 \%$ improvement in traffic speed. These first two channels correspond to short-run effects in some empirical studies that measure the effectiveness of transportation policies for congestion reduction. In these studies, the partial equilibrium welfare benefit is often the product of implied driving time savings and an estimated value of time (Anderson, 2014; Hanna et al., 2017; Adler and van Ommeren, 2016; Bauernschuster et al., 2017).

The third channel quantifies the additional change in welfare when traffic speeds adjust to clear the transportation sector. As travel speed improves with driving restrictions, people are more likely to drive on days when their vehicle usage is not restricted, which partially offsets the initial speed gains. This channel is analogous to the rebound effects found in more recent reduced-form papers that account for equilibrium responses in the transportation sector (Yang et al., 2020; Bento et al., 2020). The fourth channel, the equilibrium sorting effect, incorporates residential sorting and evaluates changes in welfare when households relocate in response to changes in the commuting utility, with housing supply held fixed. The last channel allows housing supply to adjust in response to housing price changes. In the analysis below, we sometimes refer to the first channel as the direct effect, the third channel as the rebound effect, and the second and third channels together as the equilibrium speed effect.

Before we present the simulation results, we first validate the structural model by comparing its predictions with the reduced-form evidence presented in Section 3.2. To do so, we simulate the market equilibrium under the 2008 subway network with and without the driving restriction and examine changes in the modelpredicted housing price gradient with respect to subway access. The results are reported in Appendix Table A6. The model-predicted price gradient change as a result of the driving restrictions is -0.034 , consistent with 
the reduced-form evidence that the driving restriction steepens the price gradient of subway access. ${ }^{29}$ This suggests that our structural analysis replicates well the observed pattern of equilibrium price changes under the driving restriction policy.

\section{Counterfactual Results}

We now evaluate different transportation policies and compare the equilibrium outcomes when households reoptimize both their commuting modes and their residential locations and when both the housing and transportation sectors clear. Sections 7.1 to 7.3 analyze the congestion reduction, sorting patterns, and social welfare effects in the baseline case in which housing supply is held fixed and a city-wide traffic density is used. Section 7.4 considers various extensions, including considering variable housing supply and ring roadspecific traffic density, removing random coefficients, and accounting for migration and consumption access.

Table 6 reports the results from our baseline analysis. It considers six different scenarios. The first three columns report the equilibrium outcomes under the 2008 subway network, while the next three illustrate the results under the 2014 subway network. Column (1) presents the scenario with no policies. Columns (2)-(6) describe the differences relative to Column (1). Columns (2), (3), and (4) evaluate the driving restriction, congestion pricing, and subway expansion, respectively. Columns (5) and (6) examine combinations of these policies. All results are shown separately for households with income above or below the median (high vs. low income) to reflect distributional considerations.

\subsection{Mode Choice and Congestion Reduction}

Driving Restriction Panel A of Table 6 examines changes in the travel mode and congestion. ${ }^{30}$ The driving restriction policy entails two countervailing forces. On the one hand, it moves households off the road on the $20 \%$ of workdays when driving with personal vehicles is restricted, forcing them to switch to slower modes (subway, bus, biking, walking). The increase in commuting time incentivizes households to relocate (move closer to work). Both margins of adjustments reduce congestion and increase the driving speed. On the other hand, the improved travel speed from less congestion induces households to drive more on days when vehicle usage is not restricted, especially among those with a long commute. This rebound effect dampens the congestion reduction from the direct policy effect. On average, the driving restriction increases traffic speed by $18 \%$ (from $21.5 \mathrm{~km} / \mathrm{h}$ to $25.3 \mathrm{~km} / \mathrm{h}$ ).

\footnotetext{
${ }^{29}$ The coefficient of -0.034 is smaller in magnitude than the reduced-form analysis because the reduced-form result reflects a shortrun response while the structural simulation incorporates long-run equilibrium adjustments (especially the rebound effects). The two samples are also different. The reduced-form analysis uses two years before and after CDR's initial implementation date while the structural analysis uses the 2014 cohort.

${ }^{30}$ The mode choice shares are slightly different between Table 6 and Figure 1 because the former reports mode choices among home buyers while the latter reports mode choices for all residents in Beijing, including non-home owners, who accounted for $27.8 \%$ in 2010 .
} 
Congestion Pricing Congestion pricing is levied on a per-kilometer basis and increases the driving cost at both the intensive margin (how far drivers travel) and extensive margin (whether drivers choose to drive). There are three key differences between the congestion pricing and driving restriction schemes. First, congestion pricing imposes a higher monetary cost of driving that scales with the distance traveled, while driving restrictions lead to a longer travel time. Second, congestion pricing reduces driving much more than driving restrictions among low-income households and much less among high-income households. Indeed, low-income households' driving probability is reduced by as much as $25 \%$, as they are more sensitive to congestion charges. Third, even though both policies lead to the same congestion reduction, a larger share of commuters drive under the congestion charge. This is because congestion pricing induces a stronger sorting response (more on this below), with households from both income groups and especially high-income households moving closer to work. In contrast, the commuting distance under the driving restriction barely changes. Thus, there are fewer long commutes but more people on the road under the congestion pricing than under the driving restriction scheme.

Subway Expansion Despite the immense scale of Beijing's subway expansion over 2008-2014, it leads to the smallest congestion reduction among the three policies. Column (4) demonstrates that traffic speed increases by $7 \%$, only $40 \%$ of the speed increase under the driving restriction and congestion pricing policies. The reason for this muted response is twofold. First, the reduction in the driving share is smaller under subway expansion than under the driving restriction or congestion pricing schemes. Second, and more importantly, both high- and low-income households move farther away from work and commute longer distances as the subway network expands. We discuss this below and present the spatial sorting responses in Figure 5.

These results, and especially the one on sorting, point to important channels beyond what has been covered in empirical studies that focus on the short-run impact of the subway system on traffic congestion. ${ }^{31}$ Our findings are consistent with the findings in prior literature that a) with sufficient time, induced travel demand increases one-for-one with capacity expansion (Downs, 1962; Duranton and Turner, 2011) and b) subway expansion itself lowers the cost associated with the commuting distance and increases urban sprawl (Gonzalez-Navarro and Turner, 2018; Heblich et al., 2020).

Nonetheless, the subway expansion dramatically increased subway access: the distance between home and the nearest subway station declined by about $80 \%$ for both income groups. Subway ridership increased significantly by $51 \%$ and $56 \%$ among high- and low-income groups, respectively.

Policy Combinations We now consider an array of policy mixes. We first evaluate Beijing's actual transportation policy in Column (5), which combines the subway expansion with driving restrictions. Then, in

\footnotetext{
${ }^{31}$ Using a regression discontinuity (in time) approach, Anderson (2014) finds that a 35-day transit strike that shut down subways in Los Angeles resulted in a 47\% increase in highway traffic delays during peak hours. Yang et al. (2018) shows, using a 120-day window surrounding the subway opening, that the subway expansion in Beijing from 2009 to 2015 reduced traffic congestion by $15 \%$ on average. Using a difference-in-differences framework, Gu et al. (2020) estimate that one new subway line increases traffic speed by $4 \%$ during peak hours on nearby roads based on their examination of 45 subway lines opened across 42 Chinese cities during 2016 and 2017.
} 
Column (6), we compare the existing policy to the alternative of subway expansion with congestion pricing. Subway expansion lowers the cost and increases the accessibility of public transit. The driving restriction is a command-and-control policy that leaves households with little discretion. Congestion pricing is distance based and approximates the Pigouvian tax that would internalize the congestion externality. The empirical question at hand is the extent to which congestion pricing (a market-based demand policy) exhibits stronger complementarity in reducing congestion and increasing welfare than the driving restriction (a command-andcontrol policy) when combined with subway expansion (a supply-side policy).

The improvement to driving speed under the policy combinations is close to the sum of the speed improvements under the individual policies. For example, the speed improvement is $3.83 \mathrm{~km} / \mathrm{h}$ under the driving restriction scheme, $1.49 \mathrm{~km} / \mathrm{h}$ under the subway expansion, and $5.08 \mathrm{~km} / \mathrm{h}$ under the combination of both policies. There may be two countervailing forces at play. First, the supply-side policy could complement the demand-side policy in that a larger subway network makes substitution away from driving easier. Indeed, as the subway becomes more attractive, the driving restriction lead to a 8.5-percentage-point reduction in highincome households' driving probability with the 2014 subway network in comparison to a 7.17-percentagepoint reduction with the 2008 network. On the other hand, there could be policy redundancy: some of the driving trips could be reduced under either the supply-side or the demand-side policy, leading to a smaller aggregate impact than the sum of individual policy impacts.

Our results suggest that both forces are at play. In addition, congestion pricing exhibits stronger complementarity with subway expansion than the driving restriction and is more effective in moving people off the road: the speed improvement is $5.29 \mathrm{~km} / \mathrm{h}$ in Column (6), higher than $5.08 \mathrm{~km} / \mathrm{h}$ improvement in Column (5). Congestion pricing affects both the extensive margin (the decision of whether to drive) and the intensive margin (the decision of how far to drive); both effects could be reinforced by subway expansion. In contrast, the driving restriction primarily operates along the extensive margin.

\subsection{Sorting and the Housing Price}

Sorting and Household Spatial Distribution Panel B of Table 6 examines the differential impact of the three transportation policies on households' spatial distribution. Transportation policies directly affect commuting costs. These direct changes set in motion a set of behavioral responses whereby households substitute across different travel modes and adjust their residential locations. Take driving restrictions as an example. Their direct effect pushes households to live closer to their workplaces and thereby offset the increase in commuting time when household members are forced to use a slower travel mode. On the other hand, since people are forced to drive less, congestion is reduced, and driving speed improves. This shortens the commuting time, especially for long-distance trips. For example, the driving time declines by twelve minutes for trips for which both the origin and the destination fall outside the fourth ring road (i.e., longer commuting trips) but only six minutes for other trips. In other words, the speed effect disproportionately benefits longdistance trips. Indeed, the correlation between the driving probability and driving distance increases from 
0.28 to 0.33 under the driving restriction. The speed effect undermines households' incentive to move closer to their workplaces. On net, the commuting distance remains approximately the same as before, with minimal sorting responses.

In contrast, congestion pricing is distance based and causes a much higher increase in commuting costs for longer trips. Hence, both high- and low-income groups move closer to work, as shown in Column (3). However, high-income households exhibit a much stronger sorting response for three reasons. First, $41.65 \%$ of high-income households drive to work, in comparison to $21.44 \%$ of low-income households. As a result, high-income households are much more affected by congestion pricing (which has an effect close to zero on people who do not drive). Second, high-income households have a higher WTP for commuting convenience, as their value of time is higher. Lastly, properties closer to common employment centers command a housing premium. They are more affordable for high-income than for low-income households.

Subway expansion generates the strongest sorting responses among the three policies, and these responses run in the opposite direction to those those associated with congestion pricing. The direct policy effect moves people off the road as they substitute toward subways. The improved driving speed and improved subway system make long-distance commuting by either driving or subway less costly. As a result, both the direct policy effect and the equilibrium speed effect work in the same direction and disperse households from the city center into the suburbs and locations near the new subway stations. Ultimately, the sorting response across households is dictated by changes in the commuting utility $\Delta E V$, households' idiosyncratic preferences for commuting convenience (the random coefficient of $E V$ ), and households' price sensitivity. Subway expansion creates the strongest sorting responses among the three policies because its effect is local and uneven across households: it primarily affects households experiencing changes in subway access. In contrast, both congestion pricing and driving restrictions affect the commuting costs of all households with drivers. Congestion pricing has a greater impact on households with longer driving commutes, while the effect of driving restrictions is less variable across households. One piece of supporting evidence is that the standard deviation of changes in commuting utility is several times higher under subway expansion than under congestion pricing, while that under driving restrictions is the smallest.

Figure 5 plots changes in the average commuting distances for residents in each TAZ relative to the distances in the no-policy scenario. The driving restriction leads to modest commuting distance changes that are often in opposite directions across neighborhoods. The commuting distance is reduced in almost all TAZs under congestion pricing, suggesting better spatial matches between job and housing locations. The reduction in commuting distance is most pronounced for TAZs outside the fourth ring road, where the average commuting distance is $21.9 \mathrm{~km}$, versus $11.9 \mathrm{~km}$ for households living inside the fourth ring road. In contrast, subway expansion increases the commuting distance in most TAZs, especially along the new subway lines, exacerbating "wasteful" commuting. This further separation of workplace and residence following subway expansion is consistent with the evidence in Gonzalez-Navarro and Turner (2018) and Heblich et al. (2020).

In terms of the distance to subway stations, both driving restrictions and congestion pricing result in high-income households moving closer to and low-income households moving further away from the subway 
in comparison to the outcomes under the baseline scenario. This reflects transit-based gentrification, where lower-income households are priced out of premium locations closer to the subway. Beijing's subway expansion, on the other hand, drastically reduced the distance to subway stations for both groups: the average distance to the nearest subway station dropped from $5.33 \mathrm{~km}$ to $1.19 \mathrm{~km}$ for high-income households and from $4.3 \mathrm{~km}$ to $0.86 \mathrm{~km}$ for low-income households.

Housing Price Changes in housing prices closely mirror the sorting patterns. Figure 6 exhibits the housing price responses across neighborhoods. Both driving restrictions and congestion pricing increase the prices of homes closer to job centers (such as locations inside the fourth ring road and close to the tech and financial centers), but the impact is stronger under congestion pricing. Subway expansion generates opposite spatial impacts: housing prices depreciate near the city center and appreciate in city suburbs along the new subway lines where public transportation was poor prior to the expansion. ${ }^{32}$ With both subway expansion and congestion pricing, the price impacts of subway expansion dominate.

To further illustrate the differential impact of subway expansion on home prices, Appendix Figure A8 plots the housing price gradient with respect to the subway distance separately for the 2008 and 2014 subway networks. The bid-rent curve is steeper under the 2014 network (- $¥ 1900 / \mathrm{m}^{2}$ per km) than under the 2008 network (- $¥ 700 / \mathrm{m}^{2}$ per $\mathrm{km}$ ) because the 2014 network is larger and hence the proximity to this network is more valuable to commuters. The bid-rent curve under the 2014 network shifts down, reflecting the composition change of homes whereby the subway expansion reaches cheaper homes farther away from the city center.

\subsection{Welfare Analysis}

Panel $\mathrm{C}$ of Table 6 presents the welfare results. In Figure 7, we decompose welfare changes by following equation (14) to illustrate different adjustment margins. Variable housing supply is considered in Section 7.4. Note that consumer surplus reported in this section refers to the discounted lifetime consumer surplus over the property tenure (commonly assumed to be thirty years), as discussed in Section 5.2. This is because our WTP estimates are recovered from housing transaction prices instead of the rental cost of capital.

Key Findings First, despite their effectiveness in congestion reduction, driving restrictions generate a welfare loss of $¥ 129,900$ per household over a 30-year period discounted to the present. The annualized loss is roughly $4 \%$ of the household income. ${ }^{33}$ Driving restrictions force drivers to switch to slower commuting modes and significantly increases the commuting time, especially for households with long commutes. On average, a household spends 16.8 more minutes commuting each day as a result of the driving restrictions.

\footnotetext{
${ }^{32}$ Under congestion pricing, housing prices in northwestern Beijing (near the tech center) would increase by about $2,000 ¥ / m^{2}$, while those in some southeastern areas would decrease by $2,000 ¥ / \mathrm{m}^{2}$ from a baseline average price at $24,022 ¥ / \mathrm{m}^{2}$. Under subway expansion, home prices increase by as much as $4,000 ¥ / \mathrm{m}^{2}$ in the southwest, where the subway expansion is greatest and historical prices have been lowest.

${ }^{33}$ According to the Beijing Statistics Bureau, the average household income in Beijing in 2014 was $¥ 128,000$. The average income for high- and low-income households was $¥ 172,000$ and $¥ 84,000$, respectively.
} 
High-income households experience a much steeper reduction than low-income households. As shown in Figure 7, the direct policy effect of a driving restriction is large and negative at $¥ 226,800$ per household since it distorts commuting choices and forces households to substitute toward inferior travel modes. As commuters switch to nondriving travel modes, traffic speeds and commuting time improve, mitigating the welfare loss of the direct policy effect, as shown by the second and third bars in Figure 7. The second bar highlights the effect of a partial (or short-run) speed adjustment, while the third bar represents welfare changes where the driving speed (hence congestion) and travel mode choices are in equilibrium and clear the transportation sector following equation (8). The difference between the second and third bar (a loss of $¥ 97,800$ vs. $¥ 129,200$ ) illustrates the importance of incorporating the rebound effect and allowing the full equilibrium adjustment of the transportation sector. Otherwise, the welfare effect could be overestimated by $32 \%$ for driving restrictions and by $30 \%-49 \%$ for other policies. The fourth bar further incorporates the sorting effect. With all four channels incorporated, the welfare loss is at $¥ 129,900$ per household.

Second, before revenue recycling, low-income households experience a greater loss under congestion pricing than under driving restrictions. This reflects the fact that low-income households are more responsive to increases in monetary costs from congestion pricing than they are to longer commuting times under driving restrictions. However, when the toll revenue is uniformly recycled across income groups, congestion pricing leads to welfare gains for both groups: consumer surplus increases by $¥ 39,200$ and $¥ 64,300$ for high- and low-income households, respectively. Low-income households witness a larger consumer surplus increase because they pay a smaller amount in toll charges but receive $50 \%$ of the toll revenue. This highlights the role of properly distributing toll revenues to abate distributional concerns related to congestion pricing.

In terms of the underlying channels, the direct effect of congestion pricing (with revenue recycling) reduces welfare by $¥ 30,000$ per household. The equilibrium speed effect (the partial speed and rebound effect) reverses the welfare loss to yield a welfare gain of $¥ 41,800$ per household. As sorting works in the same direction as the speed effect and moves households closer to their places of work, the welfare gain further increases to $¥ 51,800$ per household. Residential sorting enhances the welfare gain from congestion pricing by $24 \%$, consistent with the result based on 98 US cities in Langer and Winston (2008), who also finds a large benefit of congestion pricing.

Third, while the subway expansion from 2008 to 2014 resulted in limited congestion reduction relative to that under the other two policies, it leads to a larger increase in consumer surplus. Much of this increase comes from the greater access to the subway network: the distance to the nearest subway station declined by $80 \%$ on average, and subway ridership increased by more than half. Although the substitution from nondriving trips to subway trips does not alleviate traffic congestion, it improves consumer welfare by offering better commuting choices. After taking into consideration the costs of expanding and maintaining the subway, net welfare is almost halved for high-income at $¥ 117,300$ and close to zero for low-income households. The direct effect of subway expansion generates a welfare gain of $¥ 6,400$ per household as a result of improved subway accessibility. The improved driving speed in equilibrium increases consumer welfare by $¥ 53,000$ per household, with the overall welfare gain reaching $¥ 59,400$ per household. Sorting induces households to 
move away from their workplaces and the city center, which increases congestion and dampens the welfare gain to $¥ 57,100$ per household.

Fourth, the combination of congestion pricing and subway expansion achieves the largest congestion reduction (with a $25 \%$ speed improvement) and generates the highest welfare gain at $¥ 93,400$ per household over a 30-year period (about 3\% of household income) across all policy scenarios. The revenue from congestion pricing at $¥ 127,700$ per household could fully cover the costs of subway expansion at $¥ 103,000$ per household. We believe this finding has broader applicability for the design of transportation infrastructure outside the context of Beijing. ${ }^{34}$ While it is distinct from results in prior work on the role of self-financing toll roads (Mohring and Harwitz, 1962; Winston, 1991; Verhoef and Mohring, 2009), its policy implications may be greater given the severity of the congestion externality in many cities. Indeed, a broader implication of our analysis is that welfare gains from infrastructure improvements can be mitigated by induced congestion. Pairing these investments with pricing instruments such as congestion pricing is critical to successfully address pre-existing and induced congestion and increase social welfare.

Importance of Sorting and Endogenous Congestion To highlight the role of sorting and endogenous congestion, Panel A of Table 7 reports changes in speed and welfare when we shut down these channels. To facilitate comparison, the congestion price is kept the same as before at $¥ 1.13 / \mathrm{km}$. The first row of Panel A in Table 7 reproduces the baseline results from Table 6 with sorting. The second row allows the transportation sector to clear but does not allow households to relocate (i.e., sorting is shut down; Appendix Table A8 reports the full set of results). Sorting amplifies the effectiveness of congestion pricing but undermines that of subway expansion on congestion reduction. In addition, sorting increases the welfare gain from congestion pricing by as much as $40 \%$ for high-income households and 16\% for low-income households, consistent with Figure 7.

Sorting also has important distributional implications. This is most evident under subway expansion, where sorting improves the welfare of high-income households at the cost of low-income households. This reflects transit-based gentrification: both high- and low-income households prefer places near the subway, but competition from high-income households raises prices and hurts low-income households. In contrast, under congestion pricing, both groups are better off with sorting. This is because sorting (moving closer to work under congestion pricing) further reduces congestion and increases welfare. In addition, households' workplaces are not perfectly aligned, and there is room for a Pareto improvement with a better home-work match for everyone. The opposing effect of sorting on congestion pricing and subway expansion and the distributional consequences of sorting highlight the importance of accounting for sorting in the analysis. Otherwise, we risk not only overestimating or underestimating the welfare gains but also getting the signs wrong and making inappropriate policy recommendations.

The third row of Panel A in Table 7 keeps sorting but shuts down endogenous congestion. To do so, we adjust the traffic speed once in response to households' travel mode changes (the second channel in equation

\footnotetext{
${ }^{34}$ As an example, transportation funds allocated through the US American Reinvestment and Recovery Act of 2008 required several pilot pricing projects to reuse toll revenues to make enhancements to affected corridors, including public transit (GAO, 2012).
} 
(14)) but do not impose the transportation sector's equilibrium condition (8). In other words, we do not incorporate the rebound effect (the third channel in equation (14)) and do not allow the full equilibrium adjustment of the traffic speed. Households sort according to the one-time traffic speed adjustment. The results echo the point that we made above: without incorporating the full equilibrium adjustment, the speed improvement would be overestimated by $43 \%-58 \%$ and the welfare benefit inflated even more.

\subsection{Extensions and Robustness Checks}

Our baseline results in Sections 7.1 to 7.3 assume a fixed housing supply and city-wide traffic density. We relax these assumptions in Panel B of Table 7.

Housing Supply Adjustment The first row of Panel B in Table 7 summarizes the speed and welfare changes when the housing supply adjusts with the supply elasticity of 0.53 as in Wang et al. (2012). ${ }^{35}$ Appendix Table A7 reports the full set of results. To understand how housing supply adjustments affect our previous findings, consider a home whose price appreciates after a transportation policy change. This price appreciation increases housing supply, which mitigates the overall price effect. In addition, the availability of additional housing in desirable locations enhances sorting by allowing more households to move in. In other words, allowing flexibility in the housing supply magnifies the role of sorting. For example, under congestion pricing, the housing price appreciates the most around employment centers. The large housing supply response in these areas allows more people to live closer to work, further alleviating congestion. Indeed, the reduction in the commuting distance is amplified from $0.19 \mathrm{~km}$ to $0.32 \mathrm{~km}$ for high-income households and from 0.07 $\mathrm{km}$ to $0.22 \mathrm{~km}$ for low-income households with housing supply adjustment. The driving speed improvement increases from $3.83 \mathrm{~km} / \mathrm{h}$ to $3.97 \mathrm{~km} / \mathrm{h}$.

In contrast, subway expansion leads to housing price appreciation and new housing supply in city suburbs, which causes people to live farther away from work. The increase in the commuting distance deteriorates from $0.33 \mathrm{~km}$ to $0.76 \mathrm{~km}$ for high-income households and from $0.15 \mathrm{~km}$ to $0.61 \mathrm{~km}$ for low-income households. This attenuates the speed improvement under subway expansion from $1.49 \mathrm{~km} / \mathrm{h}$ to $1.13 \mathrm{~km} / \mathrm{h}$.

Ring-Specific Traffic Density The baseline analysis assumes that the geographic scope of congestion is city-wide and adjusts local speeds with a city-wide traffic density. The second row of Panel B in Table 7 incorporates ring road band-specific traffic densities and adjusts local speeds with the corresponding density in the appropriate ring road bands (Appendix Table A9 reports the full set of results). Both the average speed improvement and welfare effects are very similar to those in the baseline. Perhaps not surprisingly, the simulations with ring-specific densities deliver higher speed improvements for the fourth/fifth and fifth/sixth ring road bands but lower speed improvements toward the city center under the congestion pricing and subway expansions, both of which are more effective at moving long commutes off the road.

\footnotetext{
${ }^{35}$ The analysis is based on data for 35 Chinese cities from 1998 to 2009. Baum-Snow and Han (2021) estimate a supply elasticity of 0.3-0.5 for US cities based on data from 2000 to 2010, smaller than the estimates from Saiz (2010) based on data from 1970-2000.
} 
Exclusion of Random Coefficients The sorting model with a rich set of demographic variables and random coefficients predicts intuitive substitution patterns (Table 6). For example, under both the driving restriction and congestion pricing schemes, taxi trips account for a disproportionately higher share of the reduction in driving trips relative to the shares in other models, a pattern that holds for both the high- and low-income groups. Under the subway expansion, taxi and bus trips are affected disproportionately more. The reduction in taxi and driving trips is much larger among low-income households than among high-income households due to the former group's larger price sensitivity.

To evaluate the importance of incorporating heterogeneous preferences, we re-estimate the entire model excluding the random coefficients. We keep observed heterogeneity (e.g., income, age, gender, education, car ownership) since the model without these demographic variables has a poor fit. We repeat the counterfactual analysis in Appendix Table A10 and summarize the results in the third row of Panel B in Table 7.

While the model without random coefficients can fit the observed travel mode shares and replicate the average housing demand elasticity as in our baseline, its predictions on substitution patterns are often counterintuitive. For example, subway expansion increases ridership only by a modest $14 \%$ among high-income households instead of $51 \%$ as predicted by the baseline model. This is because the subway's market share was less than $10 \%$ in 2008 and multinomial logit-type models tend to predict "proportionate" changes (and hence a modest increase) in market share. Consequently, the model without random coefficients predicts a negligible speed improvement of $0.16 \mathrm{~km} / \mathrm{h}$, which is only $11 \%$ of the baseline prediction, and underestimates the welfare gain from subway expansion by as much as $44 \%$. In a similar vein, the model without random coefficients overestimates the value that households attach to driving, especially among high-income households, who drive more than $40 \%$ of the time. Not surprisingly, the welfare reductions associated with driving restrictions and congestion pricing are often prohibitive and several times larger than the baseline predictions.

Growing Population The baseline analysis assumes a fixed population. To account for migration, we assume in-migration of 5\% under subway expansion and out-migration of 5\% under the driving restriction and congestion pricing schemes in the fourth row of Panel B in Table 7. These choices are somewhat arbitrary but serve as upper-bound estimates of policy-induced migration since Beijing's population grew by $14 \%$ during the sample period. The speed improvement and the associated welfare under the driving restriction and congestion pricing are strengthened with out-migration, while the opposite is true for subway expansion with in-migration. Importantly, the qualitative findings remain the same as the baseline results in Table 6 .

Consumption Access Our sorting model abstracts from the endogenous availability of consumption services (e.g., restaurants, shops, and theaters) that might respond to improved traffic speeds. Estimates from recent literature (Miyauchi et al., 2021; Rao, 2021) suggest that consumer surplus from consumption access is about one-third that from job access in Tokyo and Beijing. We multiply the baseline consumer surplus by 1.33 and report the welfare changes (which also include toll revenues and subway costs) in the fifth row of Panel B in Table 7. This does not affect the baseline qualitative findings. 
Optimal Congestion Pricing Finally, we plot changes in welfare as the toll rate varies in Figure 8. The optimal congestion charge is $¥ 1.2$ per km when we shut down household sorting, ¥1.4 per km with sorting, and approximately the same when we incorporate both sorting and housing supply. At most congestion pricing levels, sorting increases consumer welfare by $20 \%-30 \%$, and supply adjustment contributes another $10 \%-20 \%$ welfare gain. In addition, changes in consumer surplus are positive for a wide range of congestion charges $(<¥ 2.5 / \mathrm{km})$. This indicates that congestion pricing is likely to be an effective tool even when governments cannot gauge the exact optimal pricing level a priori.

\section{Conclusion}

Transportation plays a critical role in determining residential locations. At the same time, household location choices help determine the efficacy and efficiency of urban transportation policies. This study provides a unified equilibrium sorting framework with endogenous congestion to empirically evaluate the efficiency and equity impacts of various urban transportation policies, incorporating rich preference heterogeneity and equilibrium feedback effects between the transportation sector and the housing market.

Our analysis delivers several important takeaways. First, including the utility from the ease of commuting in housing demand dramatically improves the model fit. Having flexible preference heterogeneity, incorporating sorting responses and modeling the joint equilibrium of the transportation sector and housing market all have important implications for the welfare and distributional outcomes. Second, compared to driving restrictions, congestion pricing better incentivizes residents to live closer to their work locations. Subway expansion does the opposite by increasing the separation between residences and workplaces. Third, the different policies generate drastically different efficiency and equity consequences. While driving restrictions reduce social welfare due to the large distortion in travel choices, congestion pricing is welfare improving for both the highand low-income groups with a uniform recycling of the revenue from the congestion charge. The combination of congestion pricing and subway expansion stands out as the best policy among all scenarios: it delivers the largest congestion reduction and the highest welfare gains. In addition, it is self-financing in that the revenue from congestion pricing can fully cover the cost of subway expansion.

Our analysis does not consider the potential implications for the labor market and firm locations, two additional channels that affect the long-term urban spatial structure. Incorporating these margins would require additional data and computational resources. We leave this task for future research. 


\section{References}

Adler, Martin W and Jos N van Ommeren, “Does public transit reduce car travel externalities? Quasi-natural experiments' evidence from transit strikes," Journal of Urban Economics, 2016, 92, 106-119.

Akbar, Prottoy, "Who Benefits from Faster Public Transit?," 2020. Working Paper.

Akbar, Prottoy A, Victor Couture, Gilles Duranton, and Adam Storeygard, "Mobility and Congestion in Urban India," Technical Report, National Bureau of Economic Research 2018.

Albouy, David and Aarsh Farahani, "Valuing Public Goods More Generally: The Case of Infrastructure,” 2017. Upjohn Institute working paper.

Allen, Treb and Costas Arkolakis, “The welfare effects of transportation infrastructure improvements,” Technical Report, National Bureau of Economic Research 2019.

Almagro, Milena and Tomás Domínguez-Iino, “Location Sorting and Endogenous Amenities: Evidence from Amsterdam,” 2020. Working Paper.

Anas, Alex and Ikki Kim, "General Equilibrium Models of Polycentric Urban Land Use with Endogenous Congestion and Job Agglomeration,” Journal of Urban Economics, September 1996, 40 (2), 232-256.

— and Robin Lindsey, "Reducing urban road transportation externalities: Road pricing in theory and in practice," Review of Environmental Economics and Policy, 2011.

Anderson, Michael L, "Subways, strikes, and slowdowns: The impacts of public transit on traffic congestion," The American Economic Review, 2014, 104 (9), 2763-2796.

Arkolakis, Costas, Arnaud Costinot, and Andrés Rodríguez-Clare, "New trade models, same old gains?," American Economic Review, 2012, 102 (1), 94-130.

Arnott, Richard, “A bathtub model of downtown traffic congestion,” Journal of Urban Economics, 2013, 76, 110-121.

Arnott, Richard J and Joseph E Stiglitz, "Aggregate land rents, expenditure on public goods, and optimal city size," The Quarterly Journal of Economics, 1979, 93 (4), 471-500.

Bajari, Patrick and Matthew E Kahn, "Estimating Housing Demand With an Application to Explaining Racial Segregation in Cities," Journal of Business \& Economic Statistics, 2005, 23 (1), 20-33.

Banzhaf, H. Spencer and V. Kerry Smith, "Meta-analysis in model implementation: choice sets and the valuation of air quality improvements," Journal of Applied Econometrics, September 2007, 22 (6), 1013-1031.

Barbanchon, Thomas Le, Roland Rathelot, and Alexandra Roulet, "Gender Differences in Job Search: Trading off Commute against Wage," The Quarterly Journal of Economics, 10 2020, 136 (1), 381-426.

Basso, Leonardo J. and Hugo E. Silva, "Efficiency and Substitutability of Transit Subsidies and Other Urban Transport Policies," American Economic Journal: Economic Policy, November 2014, 6 (4), 1-33.

Bauernschuster, Stefan, Timo Hener, and Helmut Rainer, "When labor disputes bring cities to a standstill: The impact of public transit strikes on traffic, accidents, air pollution, and health," American Economic Journal: Economic Policy, 2017,9 (1), 1-37.

Baum-Snow, Nathaniel and Lu Han, “The Microgeography of Housing Supply,” 2021. Working Paper.

Bayer, Patrick and Christopher Timmins, "On the equilibrium properties of locational sorting models," Journal of Urban Economics, 2005, 57 (3), 462-477.

_ and Robert McMillan, “Tiebout sorting and neighborhood stratification,” Journal of Public Economics, 2012,96 (11), 1129 1143 .

— , Fernando Ferreira, and Robert McMillan, "A Unified Framework for Measuring Preferences for Schools and Neighborhoods," Journal of Political Economy, August 2007, 115 (4), 588-638. 
_ , Nathaniel Keohane, and Christopher Timmins, "Migration and hedonic valuation: The case of air quality," Journal of Environmental Economics and Management, July 2009, 58 (1), 1-14.

_ , Robert McMillan, Alvin Murphy, and Christopher Timmins, "A Dynamic Model of Demand for Houses and Neighborhoods," Econometrica, 2016, 84 (3), 893-942.

_ , _ , and Kim Rueben, "An equilibrium model of sorting in an urban housing market," Technical Report, National Bureau of Economic Research 2004.

Bento, Antonio, Jonathan Hall, and Kilian Heilmann, "Estimating Congestion Externalities Using Big Data," Technical report, 2020.

Bento, Antonio M, Lawrence H Goulder, Mark R Jacobsen, and Roger H Von Haefen, "Distributional and efficiency impacts of increased US gasoline taxes," American Economic Review, 2009, 99 (3), 667-99.

Bento, Antonio M., Maureen L. Cropper, Ahmed Mushfiq Mobarak, and Katja Vinha, “The Effects of Urban Spatial Structure on Travel Demand in the United States," The Review of Economics and Statistics, 2005, 87 (3), 466-478.

Berry, Steven, James Levinsohn, and Ariel Pakes, “Automobile prices in market equilibrium,” Econometrica, 1995, pp. 841-890.

Brownstone, David and Kenneth A. Small, "Valuing time and reliability: assessing the evidence from road pricing demonstrations," Transportation Research Part A: Policy and Practice, 2005, 39 (4), 279 - 293.

Brueckner, Jan K, "The structure of urban equilibria: A unified treatment of the Muth-Mills model," Handbook of regional and urban economics, 1987, 2, 821-845.

_ , "Urban growth boundaries: An effective second-best remedy for unpriced traffic congestion?, Journal of Housing Economics, 2007, 16 (3-4), 263-273.

Buchholz, Nicholas, Laura Doval, Jakub Kastl, Filip Matejka, and Tobias Salz, “The Value of Time: Evidence From AuctionedCab Rides," 2020. Working Paper.

Calder-Wang, Sophie, “The Distributional Impact of the Sharing Economy on the Housing Market," 2020. Working Paper.

Capps, Cory, David Dranove, and Mark Satterthwaite, "Competition and market power in option demand markets," RAND Journal of Economics, 2003, pp. 737-763.

Couture, Victor, Cecile Gaubert, Jessie Handbury, and Erik Hurst, "Income Growth and the Distributional Effects of Urban Spatial Sorting," NBER Working Paper No. 26142, 2020.

Davis, Lucas W., "The Effect of Driving Restrictions on Air Quality in Mexico City," Journal of Political Economy, 2008, 116, $38-81$.

Diamond, Rebecca, "The determinants and welfare implications of US workers' diverging location choices by skill: 1980-2000," The American Economic Review, 2016, 106 (3), 479-524.

Downs, Anthony, “The Law of Peak-Hour Expressway Congestion,” Traffic Quarterly, 1962, 16 (3), 393-409.

Duranton, Gilles and Matthew A. Turner, "Fundamental Law of Road Congestion: Evidence from U.S. Cities.," American Economic Review, 2011, 101(October).

Epple, Dennis and Holger Sieg, "Estimating Equilibrium Models of Local Jurisdictions," Journal of Political Economy, 1999,107 (4), 645-681.

_ , Richard Romano, and Holger Sieg, “The intergenerational conflict over the provision of public education,” Journal of Public Economics, 2012, 96 (3), 255 - 268.

Fajgelbaum, Pablo D and Edouard Schaal, "Optimal transport networks in spatial equilibrium,” Econometrica, 2020, 88 (4), 1411-1452.

Ferreira, Fernando and Maisy Wong, "Estimating Preferences for Neighborhood Amenities Under Imperfect Information,” NBER Working Paper 28165, 2021. 
Ferreyra, Maria Marta, "Estimating the effects of private school vouchers in multidistrict economies," American Economic Review, 2007, 97 (3), 789-817.

Gallego, Francisco, Juan-Pablo Montero, and Christian Salas, "The effect of transport policies on car use: Evidence from Latin American cities," Journal of Public Economics, 2013, 107, 47-62.

GAO, "Report to the Subcommittee on Transportation, Housing, and Urban Development and Related Agencies, Committee on Appropriations, House of Representatives: TRAFFIC CONGESTION: Road Pricing Can Help Reduce Congestion, but Equity Concerns May Grow,” Technical Report 2012.

Glaeser, Edward L, Matthew E Kahn, and Jordan Rappaport, "Why do the poor live in cities? The role of public transportation," Journal of urban Economics, 2008, 63 (1), 1-24.

Goldszmidt, Ariel, John A. List, Robert D. Metcalfe, Ian Muir, V. Kerry Smith, and Jenny Wang, "The Value of Time in the United States: Estimates from a Nationwide Natural Field Experiment,” 2020. Working Paper.

Gonzalez-Navarro, Marco and Matthew A. Turner, "Subways and urban growth: Evidence from earth," Journal of Urban Economics, November 2018, 108, 85-106.

Gu, Yizhen, Jiang Chang, Junfu Zhang, and Ben Zou, “Subways and Road Congestion,” American Economic Journal: Applied Economics, 2020. forthcoming.

Guevara, C. Angelo and Moshe E. Ben-Akiva, "Sampling of alternatives in Logit Mixture models," Transportation Research Part B: Methodological, 2013, 58, 185 - 198.

Hainmueller, Jens, "Entropy Balancing for Causal Effects: A Multivariate Reweighting Method to Produce Balanced Samples in Observational Studies," Political Analysis, 2012, 20 (1), 25 ?46.

Hall, Jonathan D., "Pareto improvements from Lexus Lanes: The effects of pricing a portion of the lanes on congested highways," Journal of Public Economics, 2018, 158, 113 - 125.

Han, Bing, Lu Han, and Guozhong Zhu, "Housing Price and Fundamentals in A Transition Economy: The Case of The Beijing Market,” International Economic Review, 2018, 59 (3), 1653-1677.

Hanna, Rema, Gabriel Kreindler, and Benjamin A Olken, "Citywide effects of high-occupancy vehicle restrictions: Evidence from "three-in-one" in Jakarta," Science, 2017, 357 (6346), 89-93.

Heblich, Stephan, Stephen J Redding, and Daniel M Sturm, "The Making of the Modern Metropolis: Evidence from London," The Quarterly Journal of Economics, 05 2020, 135 (4), 2059-2133.

Hwang, Yujung, “An Estimable General-Equilibrium Structural Model of Immigrants' Neighborhood Sorting and Social Integration,” 2019. Working Paper.

Jerch, Rhiannon, Panle Jia Barwick, Shanjun Li, and Jing Wu, "Road Rationing Policies and Housing Markets,” 2021. Working Paper.

Klaiber, Allen H. and Daniel J. Phaneuf, "Valuing open space in a residential sorting model of the Twin Cities," Journal of Environmental Economics and Management, September 2010, 60 (2), 57-77.

Kreindler, Gabriel E., “The Welfare Effect of Road Congestion Pricing: Experimental Evidence and Equilibrium Implications," 2018. Working Paper.

Kuminoff, Nicolai V., "Decomposing the structural identification of non-market values," Journal of Environmental Economics and Management, March 2009, 57 (2), 123-139.

Kuminoff, Nicolai V, "Partial identification of preferences in a dual-market sorting equilibrium," 2012. Working Paper.

Kuminoff, Nicolai V., V. Kerry Smith, and Christopher Timmins, "The New Economics of Equilibrium Sorting and Policy Evaluation Using Housing Markets," Journal of Economic Literature, December 2013, 51 (4), 1007-1062.

Lancaster, Kelvin, Consumer Demand: A New Approach, Columbia University Press, 1971. 
Langer, Ashley and Clifford Winston, "Toward a Comprehensive Assessment of Road Pricing Accounting for Land Use," Brookings-Wharton Papers on Urban Affairs, 2008, pp. 127-175.

LeRoy, Stephen F and Jon Sonstelie, "Paradise lost and regained: Transportation innovation, income, and residential location," Journal of Urban Economics, 1983, 13 (1), 67-89.

Li, Shanjun, "Better lucky than rich? Welfare analysis of automobile license allocations in Beijing and Shanghai," Review of Economic Studies, 2018, 85 (4), 2389-2428.

_ , Joshua Linn, and Erich Muehlegger, “Gasoline taxes and consumer behavior,” American Economic Journal: Economic Policy, 2014, 6 (4), 302-42.

_ , Yanyan Liu, Avralt-Od Purevjav, and Lin Yang, “Does subway expansion improve air quality?, Journal of Environmental Economics and Management, 2019, 96, 213 - 235.

Liu, Youming, Shanjun Li, and Caixia Shen, "The Dynamic Efficiency in Resource Allocation: Evidence from Vehicle License Lotteries in Beijing," Working Paper 26904, National Bureau of Economic Research March 2020.

Miyauchi, Yuhei, Kentaro Nakajima, and Stephen J Redding, "Consumption Access and the Spatial Concentration of Economic Activity: Evidence from Smartphone Data,” Working Paper 28497, National Bureau of Economic Research February 2021.

Mohring, Herbert and Mitchell Harwitz, Highway Benefits: An Analytical Framework, Northwestern University Press, 1962.

Murphy, Alvin, “A Dynamic Model of Housing Supply,” Available at SSRN 2200459, 2015.

Parry, Ian WH and Kenneth A Small, "Does Britain or the United States have the right gasoline tax?," American Economic Review, 2005, 95 (4), 1276-1289.

_ and _ , "Should Urban Transit Subsidies Be Reduced?," The American Economic Review, 2009, 99 (3), $700-724$.

Petrin, Amil, "Quantifying the Benefit of New Products: the Case of Minivan,” Journal of Political Economy, 2002, 110 (4), $705-$ 729.

Phaneuf, Daniel J, V Kerry Smith, Raymond B Palmquist, and Jaren C Pope, "Integrating Property Value and Local Recreation Models to Value Ecosystem Services in Urban Watersheds," Land Economics, 2008, 84 (3), 361-381.

Rao, Deyu, "The Role of Environmental Amenities in the Urban Economy: Evidence from a Spatial General Equilibrium Approach," 2021. Working Paper.

Redding, Stephen J. and Esteban Rossi-Hansberg, "Quantitative Spatial Economics,” Annual Review of Economics, 2017, 9 (1), $21-58$.

Saiz, Albert, “The geographic determinants of housing supply,” The Quarterly Journal of Economics, 2010, 125 (3), $1253-1296$.

Severen, Christopher, “Commuting, Labor, and Housing Market Effects of Mass Transportation: Welfare and Identification,” 2019. Working Paper.

Sieg, Holger, V Kerry Smith, H Spencer Banzhaf, and Randy Walsh, "Estimating the general equilibrium benefits of large changes in spatially delineated public goods," International Economic Review, 2004, 45 (4), 1047-1077.

Small, Kenneth A., "Valuation of travel time," Economics of Transportation, 2012, 1 (1-2), 2-14.

Small, Kenneth A, Clifford Winston, and Jia Yan, "Uncovering the distribution of motorists' preferences for travel time and reliability," Econometrica, 2005, 73 (4), 1367-1382.

_ , Erik T Verhoef, and Robin Lindsey, The Economics of Urban Transportation, Routledge, 2007.

Stiglitz, Joseph E, "The theory of local public goods," in "The economics of public services," Springer, 1977, pp. 274-333.

Timmins, Christopher and Jennifer Murdock, "A revealed preference approach to the measurement of congestion in travel cost models," Journal of Environmental Economics and management, 2007, 53 (2), 230-249.

Train, Kenneth E. and Clifford Winston, "Vehicle Choice Behavior and the Declining Market Share of U.S. Automakers," Inter- 
national Economic Review, 2007, 48, 1469-1496.

Tsivanidis, Nick, “Evaluating the Impact of Urban Transit Infrastructure: Evidence from Bogota’s TransMilenio,” 2019. Working Paper.

USDOT, "Revised departmental guidance on valuation of travel time in economic analysis," 2015. US Department of Transportation, Washington, DC.

Verhoef, Erik T. and Herbert Mohring, "Self-Financing Roads," International Journal of Sustainable Transportation, 2009,3 (5-6), 293-311.

Viard, V Brian and Shihe Fu, "The effect of Beijing's driving restrictions on pollution and economic activity," Journal of Public Economics, 2015, 125, 98-115.

Vickrey, William, "Pricing in Urban and Suburban Transport," American Economic Review, 1963, 53 (2), $452-465$.

Walsh, Randy et al., "Endogenous open space amenities in a locational equilibrium," Journal of urban Economics, 2007, 61 (2), 319-344.

Wang, Songtao, Su Han Chan, and Bohua Xu, "The Estimation and Determinants of the Price Elasticity of Housing Supply: Evidence from China," Journal of Real Estate Research, 2012, 33 (3), 311-344.

Wang, Wen, "Environmental Gentrification,” Working Paper, 2020.

Wasi, Nada and Michael P. Keane, "Estimation of Discrete Choice Models with Many Alternatives Using Random Subsets of the Full Choice Set: With an Application to Demand for Frozen Pizza,” Working Paper, 2012.

Waxman, Andrew, "The Long Road to Work: The Divergent Effects of Transportation Policies by Worker Skill in a Locational Sorting Model," working paper, 2017.

Winston, Clifford, "Efficient Transportation Infrastructure Policy,” The Journal of Economic Perspectives, 1991, 5 (1), $113-127$.

Wolff, Hendrik, "Value of time: Speeding behavior and gasoline prices," Journal of Environmental Economics and Management, 2014, 67 (1), 71-88.

Xiao, Junji, Xiaolan Zhou, and Wei-Min Hu, "Welfare Analysis of the Vehicle Quota System in China," International Economic Review, 2017, 58 (2), 617-650.

Yang, Jun, Avralt-Od Purevjav, and Shanjun Li, "The Marginal Cost of Traffic Congestion and Road Pricing: Evidence from a Natural Experiment in Beijing," American Economic Journal: Economic Policy, 2020, 12 (1), 418-453.

— , Shuai Chen, Ping Qin, Fangwen Lu, and Antung A Liu, “The Effect of Subway Expansions on Vehicle Congestion: Evidence from Beijing," Journal of Environmental Economics and Management, 2018, 88, 114-133.

Zhang, Wei, C-Y Cynthia Lin Lawell, and Victoria I Umanskaya, "The effects of license plate-based driving restrictions on air quality: Theory and empirical evidence," Journal of Environmental Economics and Management, 2017, 82, 181-220. 
Figure 1: Travel Patterns for Commuting Trips from Beijing Household Travel Survey

(a) Year 2010 vs. Year 2014

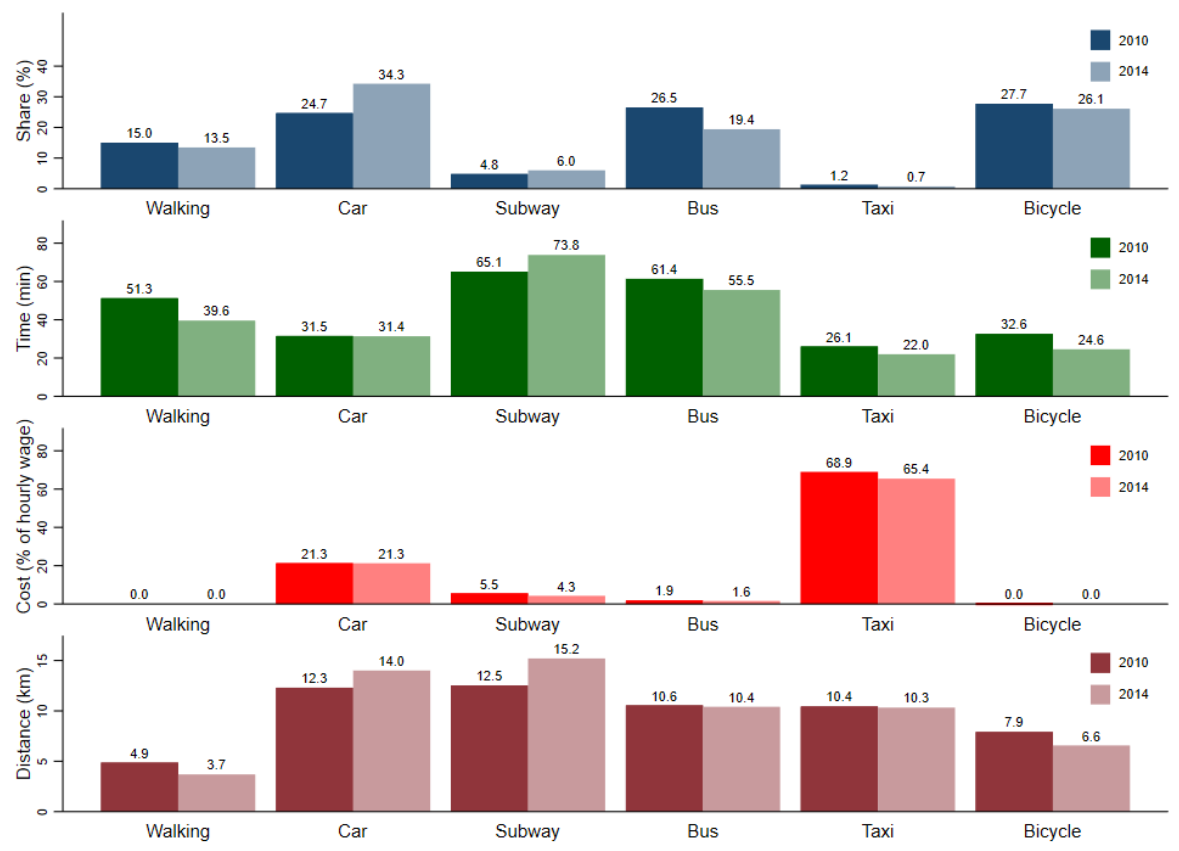

(b) High-income vs. Low-income Households
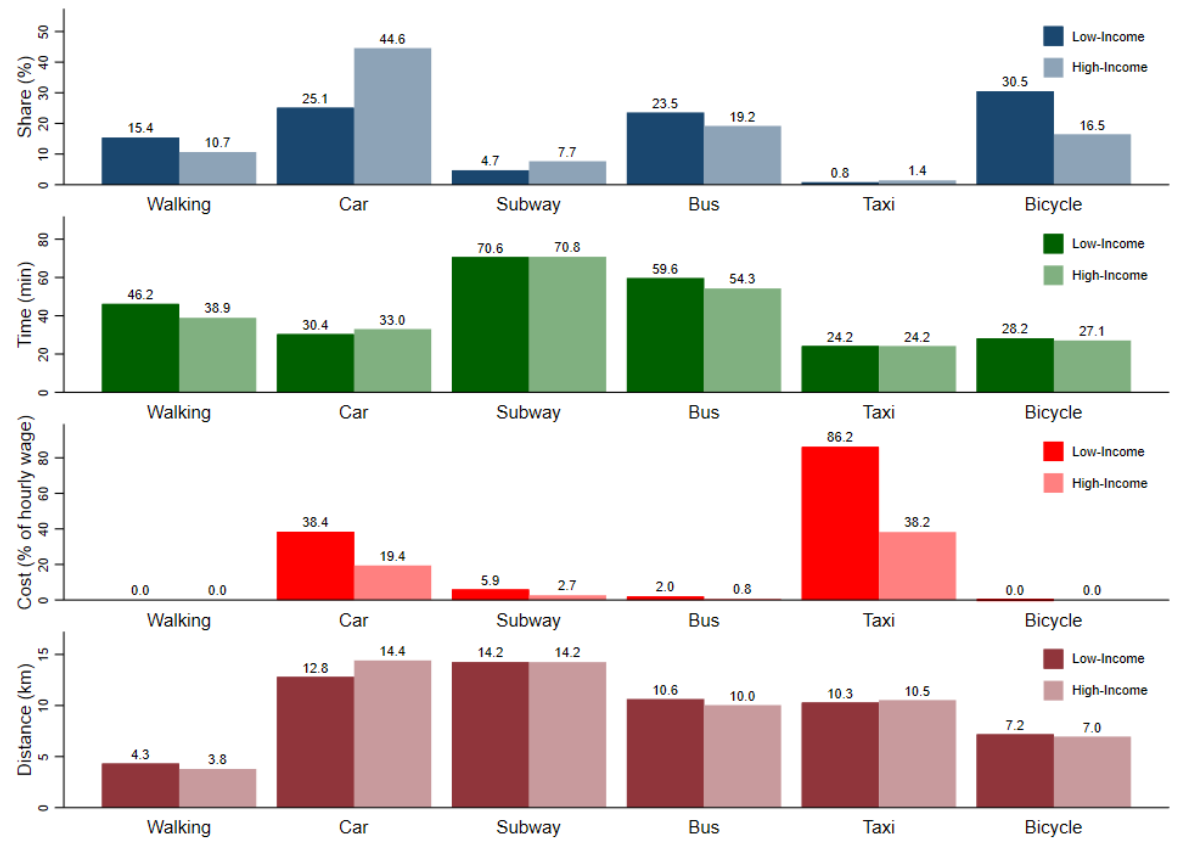

Note: This figure plots the trip share, time, costs, and average distance by travel modes for work commuting trips in the Beijing Household Travel Survey of 2010 and 2014. There are six main trip modes: walk, bike, bus, subway, car, and taxi. Bus and subway trips could include segments with other modes but we characterize them as bus and subway trips. Trips using both bus and subway are rare (less than 3\% in the data and are dropped in the analysis.) Travel time, cost (defined as \% of hourly wage), and distance are constructed as in Appendix A.1. High-income households are defined as households whose income is greater than the median in the survey year. 
Figure 2: Housing and Household Attributes from Mortgage Data

(a) Housing Price $\left(¥ / \mathrm{m}^{2}\right)$

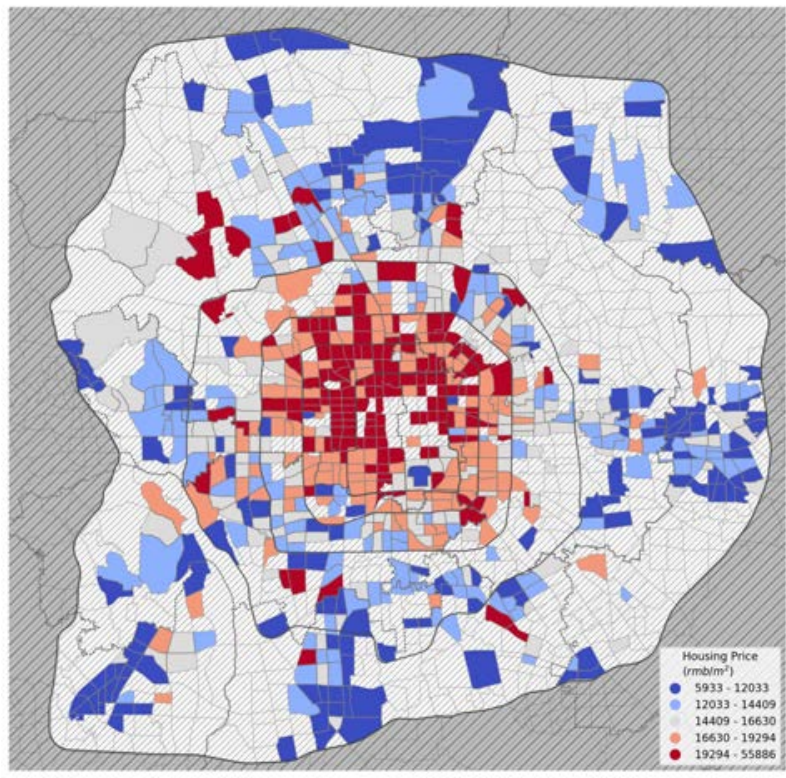

(c) Distance to Work (m)

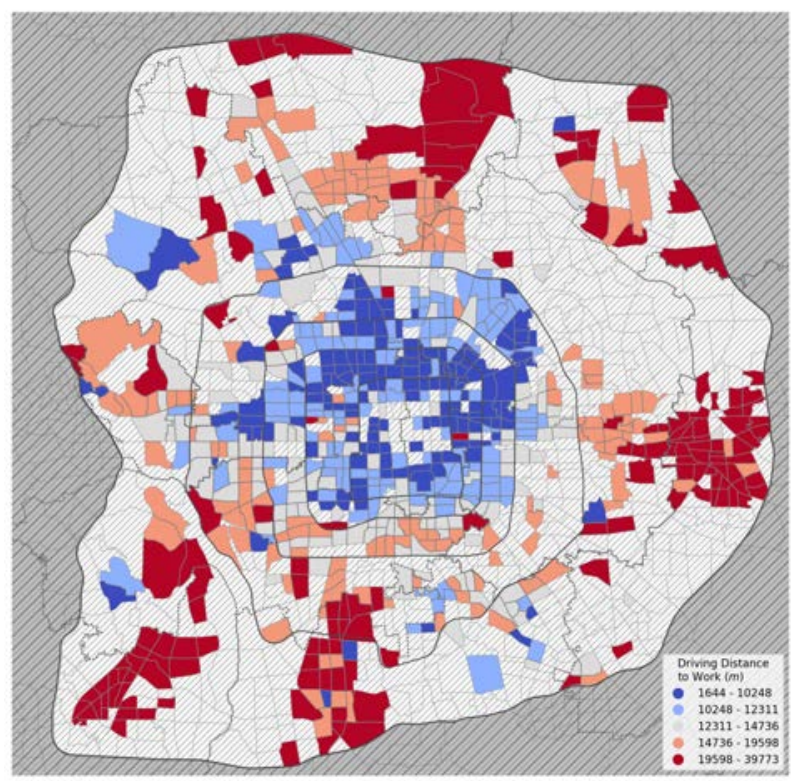

(b) Housing Size $\left(\mathrm{m}^{2}\right)$

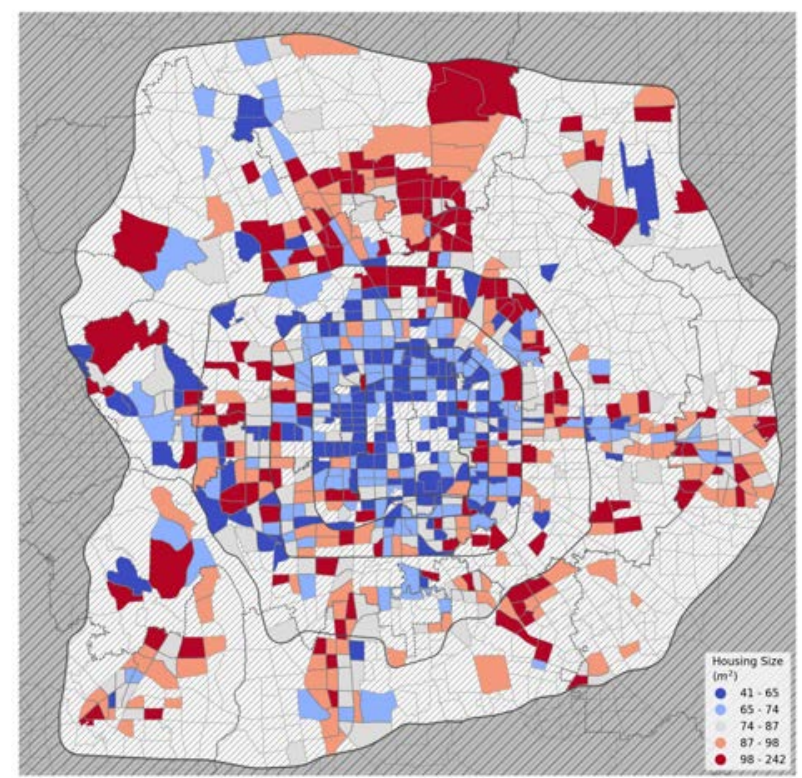

(d) Monthly Household Income (¥)

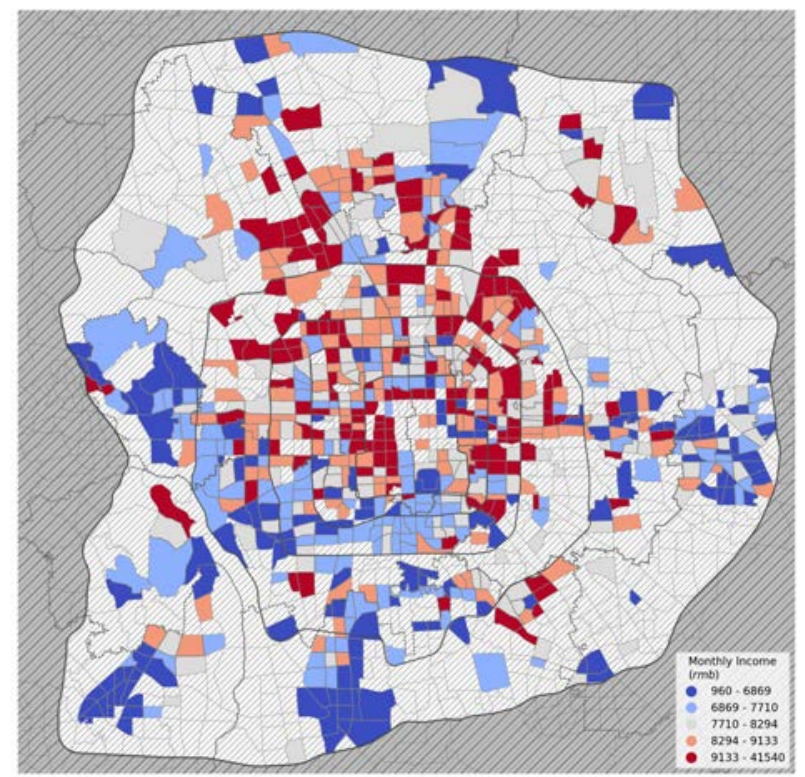

Note: This figure plots the average housing price and size and household commuting distance and monthly income by Traffic Analysis Zones (TAZ) based on the 2006-2014 mortgage data. TAZs are standardized spatial units used by transportation planners. There were 2050 TAZs in Beijing in 2014. Distance to work is the driving distance for all borrowers in the data (including primary and secondary borrowers when both are present). Monthly household income is measured at the time of purchase. Warmer colors (red and orange) correspond to larger values while colder colors (dark and light blue) correspond to lower values. TAZs with no observations are blank. 
Figure 3: Welfare under Congestion Pricing and Driving Restriction in Partial Equilibrium

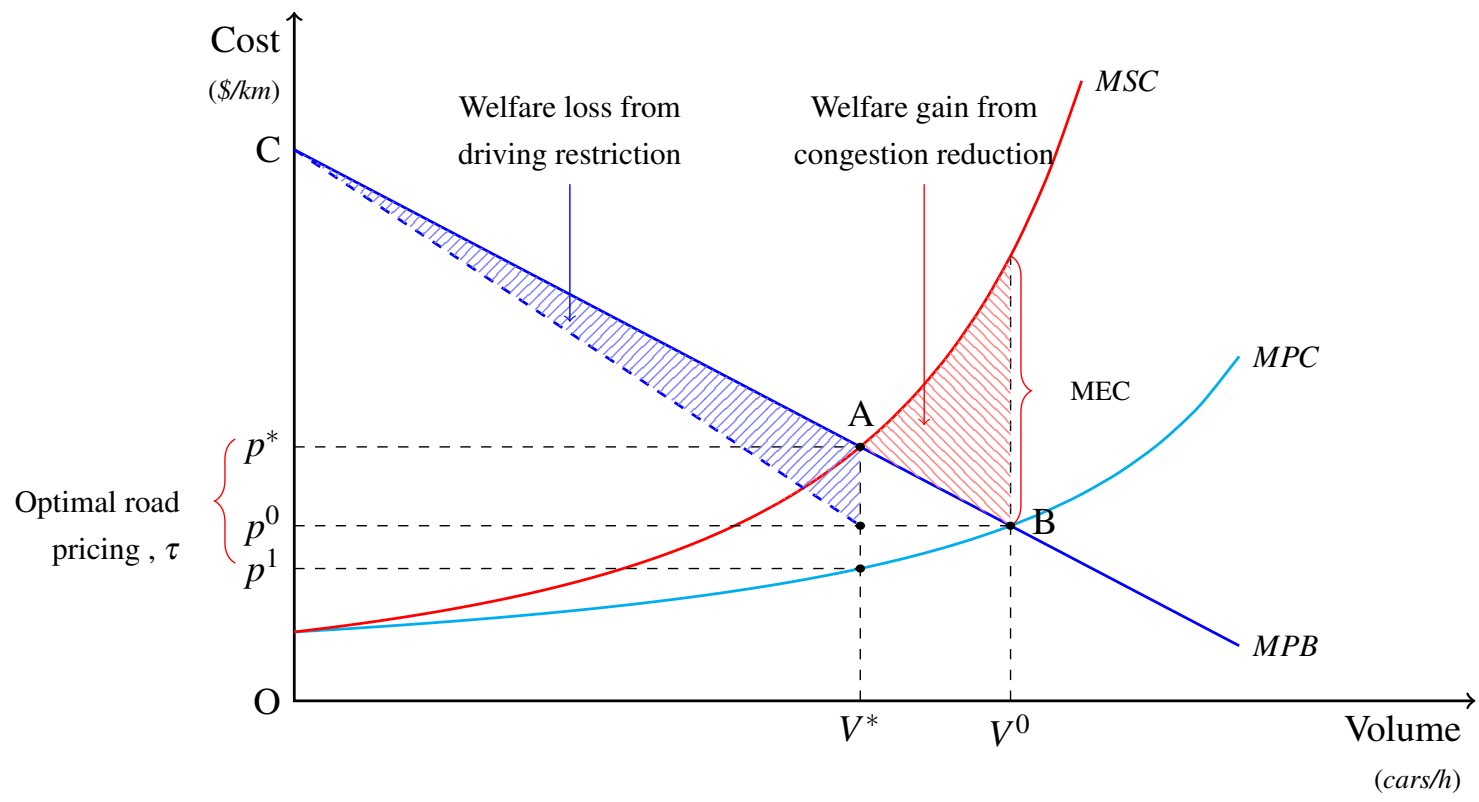

Note: The figure illustrates the welfare impacts of optimal congestion pricing and driving restriction. The $\mathrm{x}$-axis denotes traffic volume (measured by the number of cars per hour passing a location). The marginal private benefit $M P B$ curve represents demand for driving (willingness to pay for driving). The marginal private cost $M P C$ curve reflects the private cost of driving, while the marginal social cost $M S C$ curve reflects changes in the aggregate commuting costs by all drivers when there is an additional driver on the road. The difference between the private cost $M P C$ and the social cost $M S C$ is the congestion externality (or the marginal external cost of congestion, $M E C$ ). In the absence of any intervention, equilibrium occurs at $V^{0}$. The shaded red area shows the deadweight loss due to excess congestion. Congestion pricing (i.e., a Pigouvian tax), $\tau$, can be imposed to achieve the socially optimal level of traffic volume $V^{*}$. Different from congestion pricing, a driving restriction is a command-and-control approach and eliminates trips at all levels of marginal benefit. Assuming that the driving restriction results in a random reduction of trips from $V^{0}$ to $V^{*}$, total consumer surplus is reduced in proportionate to $\frac{V^{0}}{V^{*}}$ of that from no policy, i,e., from $\mathrm{CB} V^{0} \mathrm{O}$ to $\mathrm{CA} V^{*} \mathrm{O}$. Taking into consideration the changes in the aggregated social costs of driving, a driving restriction involves additional welfare losses as shaded in blue compared to congestion pricing. Therefore, the welfare impact of the driving restriction is ambiguous $a$ priori. We abstract away from potential income effects that arise from the congestion pricing, which can be offset by recycling the toll revenue. 
Figure 4: Reduced-Form Evidence on Housing Price Gradient before and after Driving Restriction

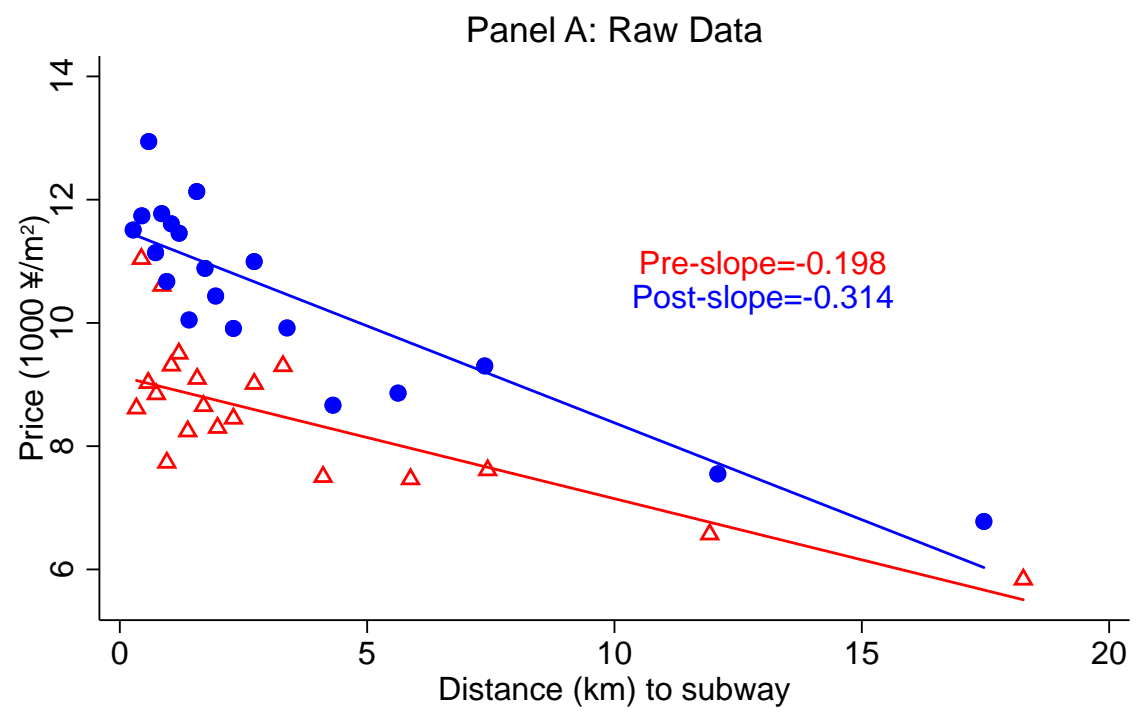

\begin{tabular}{llll|}
\hline$\Delta$ & Pre-Driving Restriction & $\bullet$ & Post-Driving Restriction \\
& Pre-Driving Restriction & Post-Driving Restriction \\
\hline
\end{tabular}

Panel B: Residualized

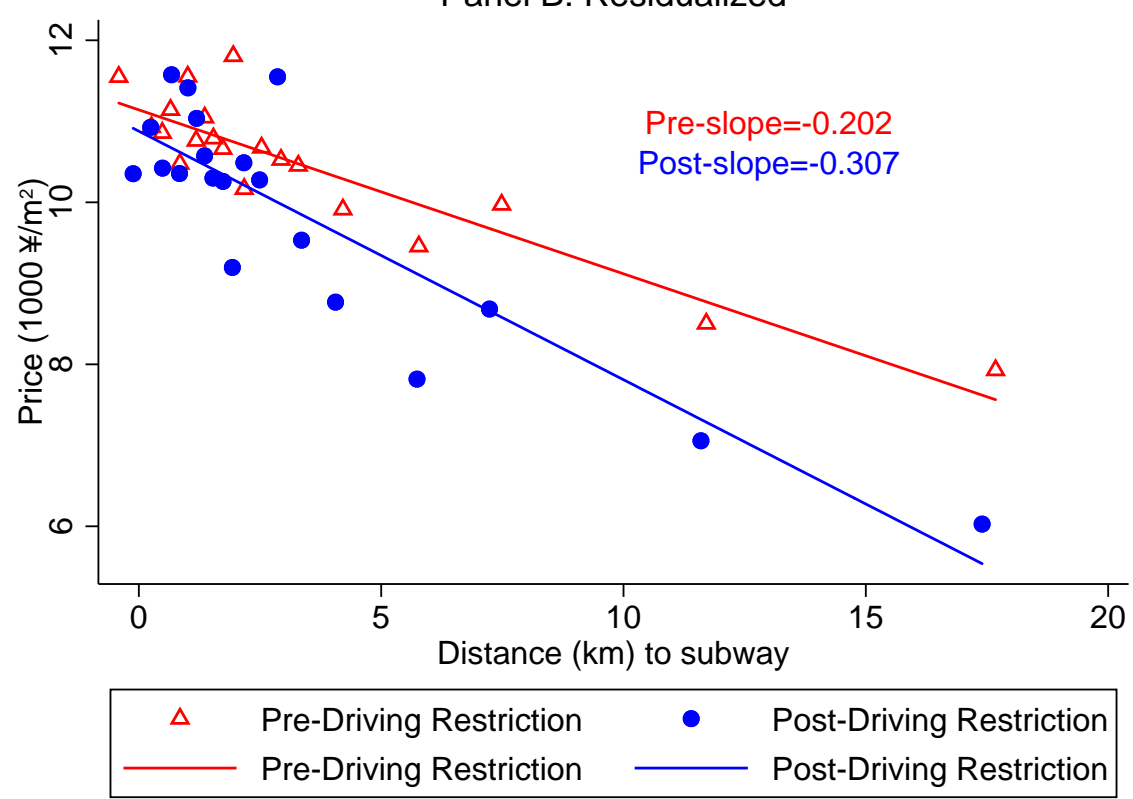

Notes: These binned scatterplots display housing price in $¥ 1000$ s per square meter against distance to nearest subway stations before and after the driving restriction. The sample spans 24 months before and after the policy's starting point (July 2008) with 23,917 observations. The top panel is based on raw prices. The bottom panel controls for neighborhood fixed effects, and year by month fixed effects and presents residualized prices. The slopes are based on linear fits. 
Figure 5: Changes in Commuting Distances from Counterfactual Simulations (in meters)

(a) Driving Restriction

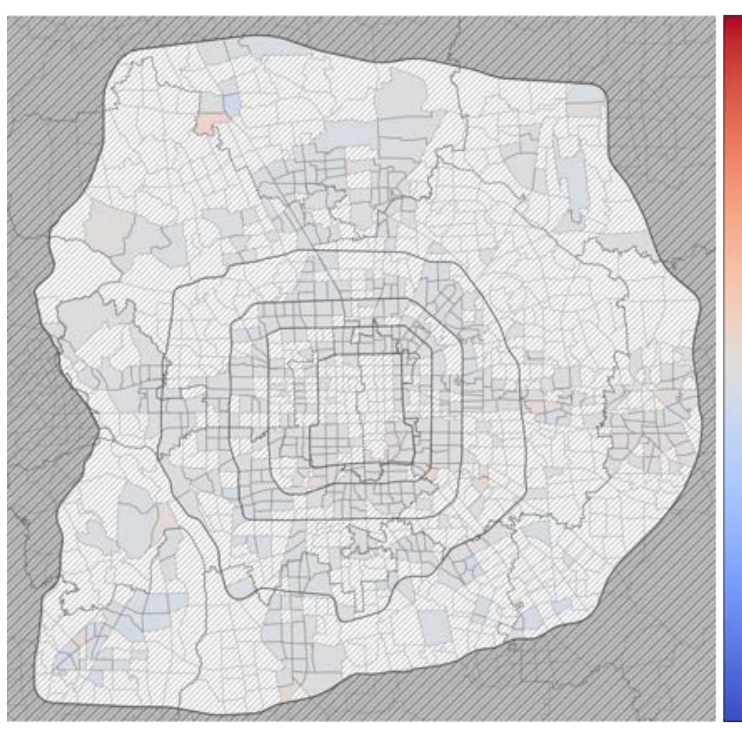

(c) Subway Expansion

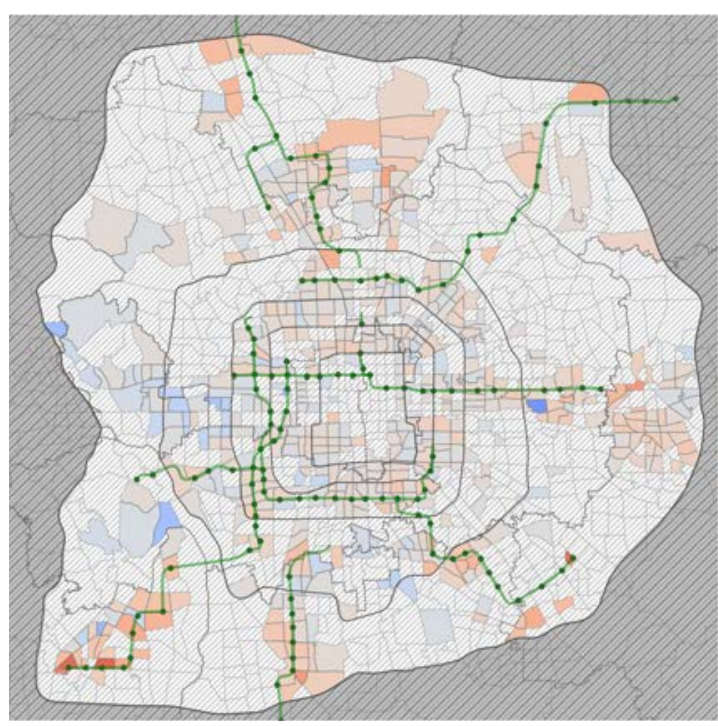

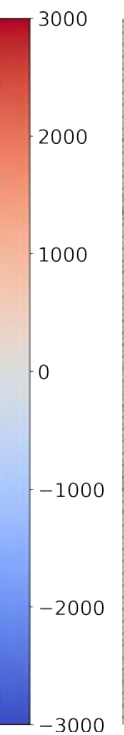

$-3000$

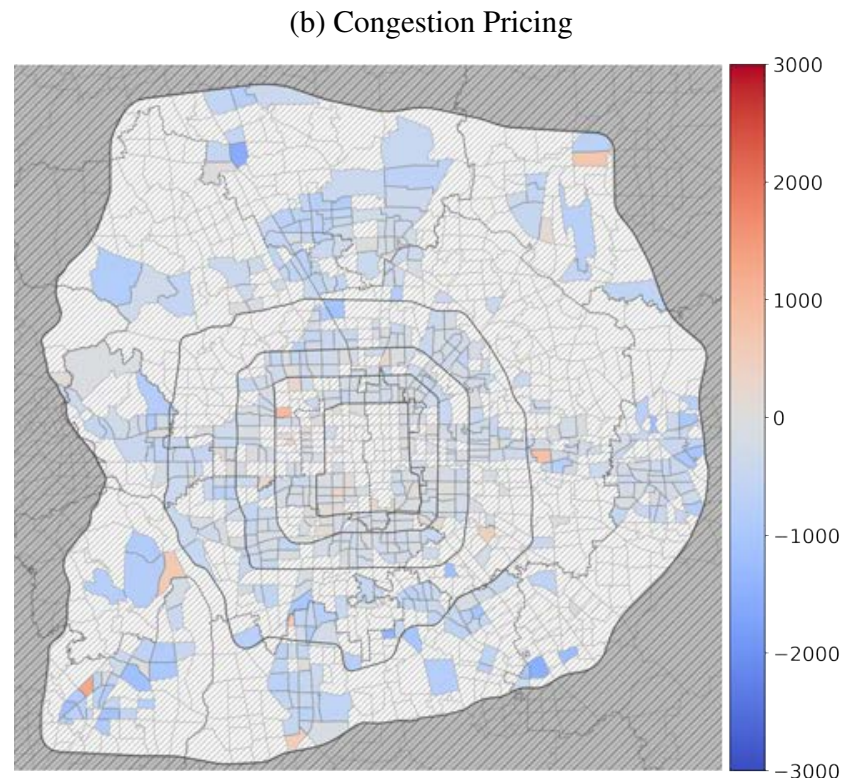

(d) Subway Expansion + Congestion Pricing

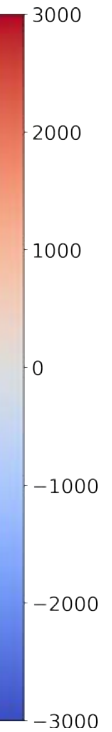

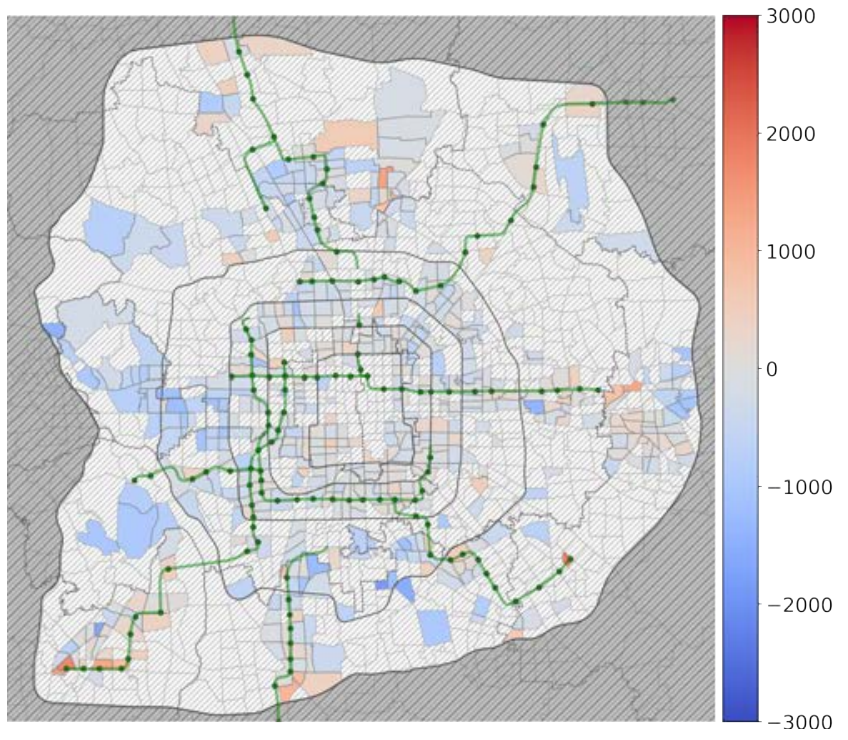

Note: This figure illustrates simulated changes in commuting distances (in meters) across TAZs under different counterfactual policies (relative to the no policy scenario). The results are based on the simulations in Table 6. Warmer colors correspond to increases in commuting distance while colder colors represent decreases. Green lines represent new subway lines built between year 2008 and 2014. 
Figure 6: Changes in Housing Prices from Counterfactual Simulations (in $¥ / m^{2}$ )

(a) Driving Restriction

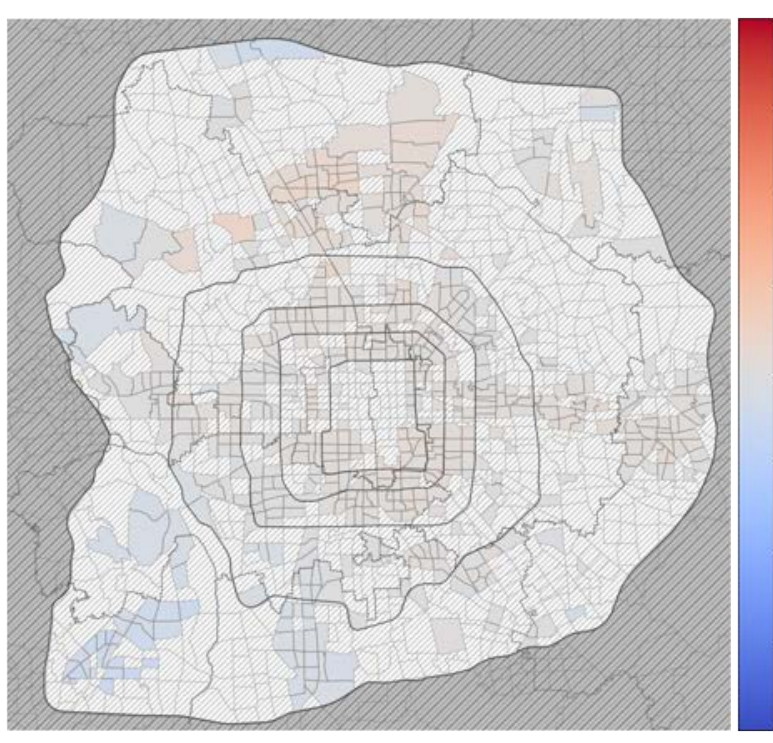

(c) Subway Expansion

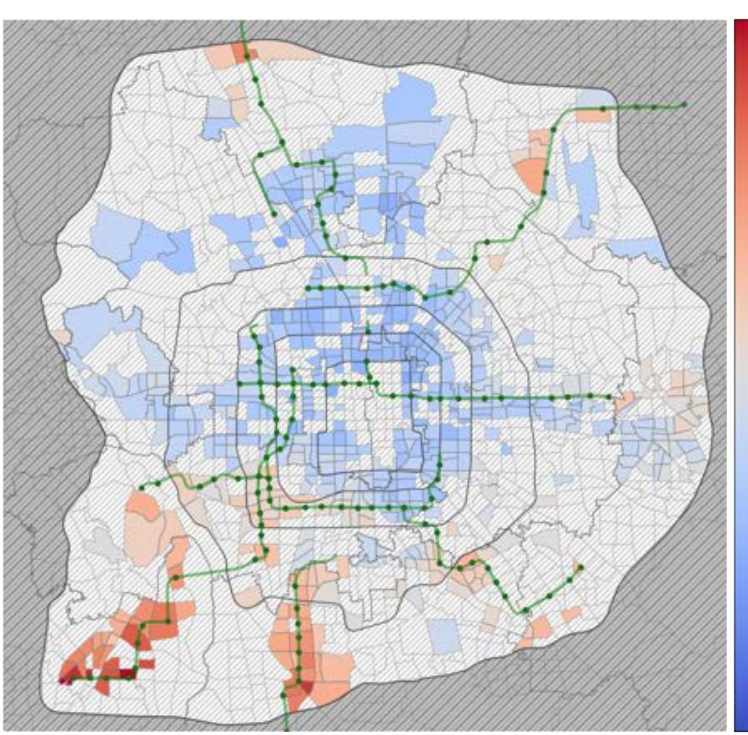

(b) Congestion Pricing
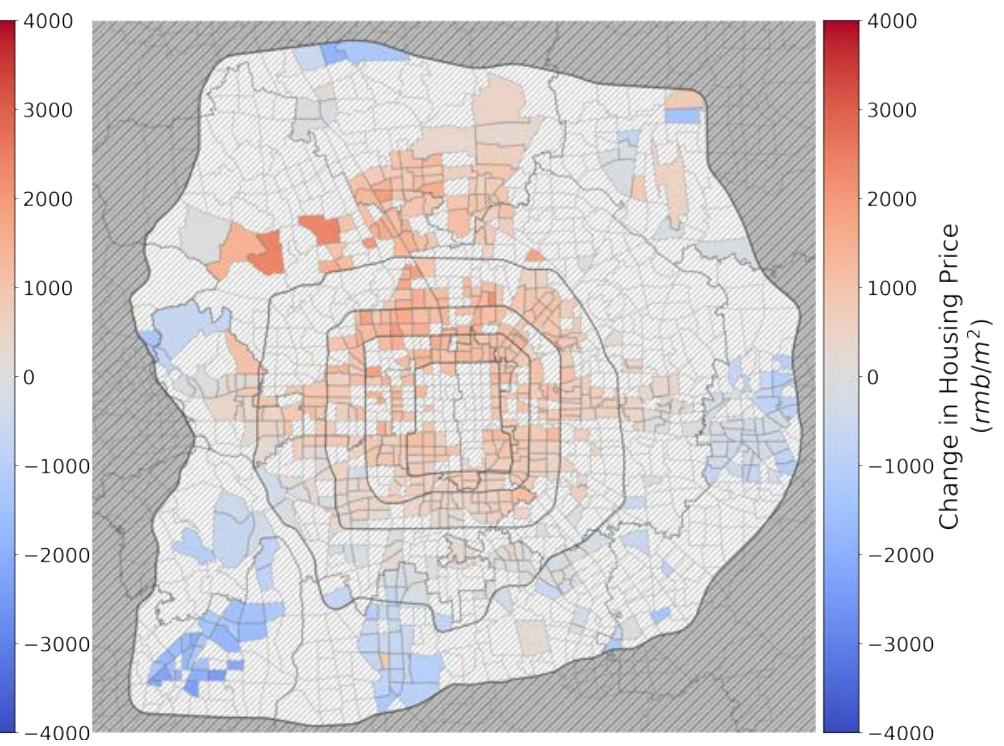

(d) Subway Expansion + Congestion Pricing

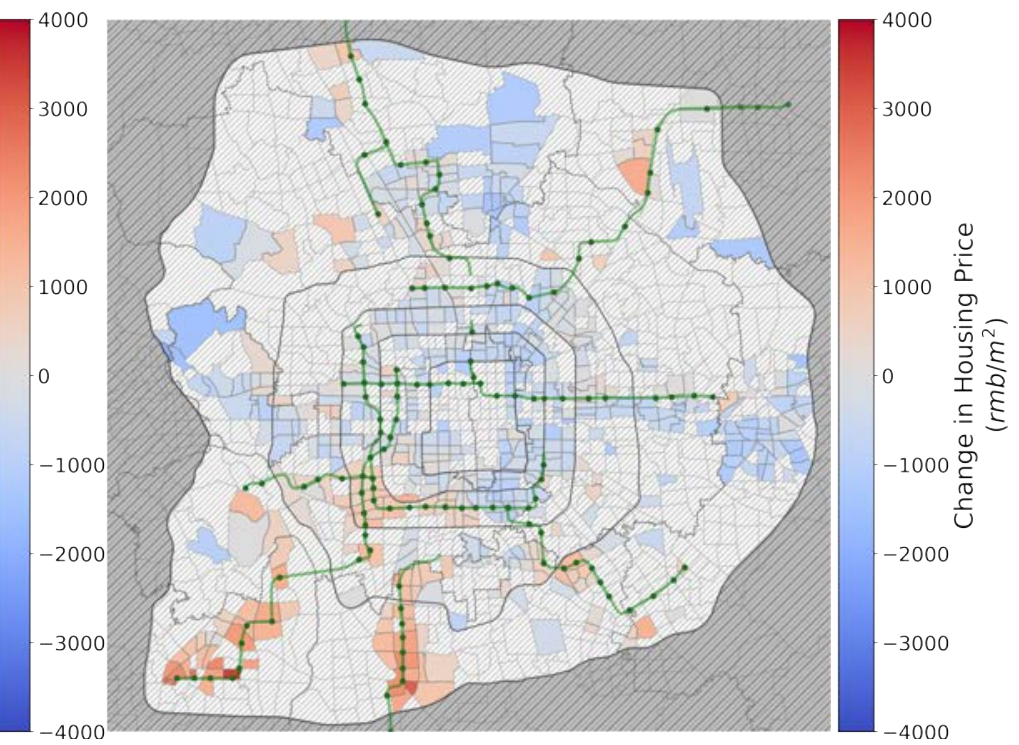

Note: This figure illustrates simulated changes in housing prices (in $¥ / \mathrm{m}^{2}$ ) across TAZs under different counterfactual policies (relative to the no policy scenario). The results are based on the simulations in Table 6. Warmer colors correspond to increases in commuting distance while colder colors represent decreases. Green lines represent new subway lines built between year 2008 and 2014. 
Figure 7: Welfare Decomposition for Different Transportation Policies

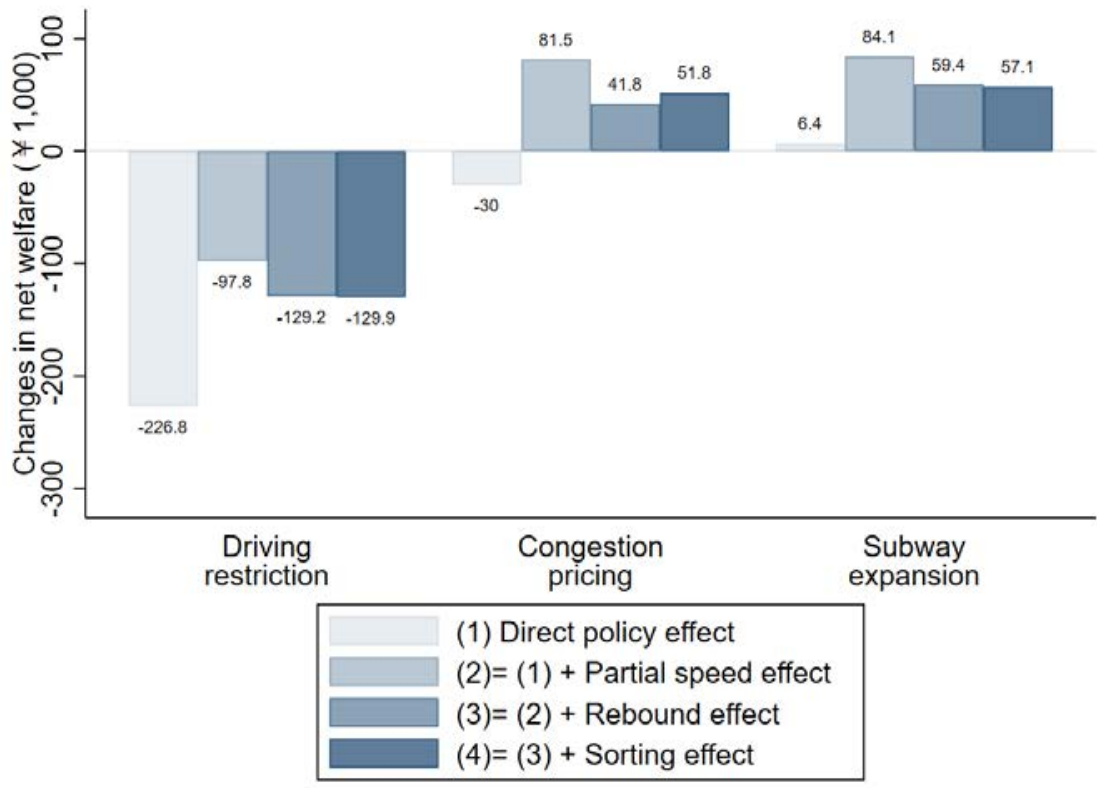

Notes: This figure decomposes welfare changes per household along four adjustment margins. For each policy, the bars display the cumulative welfare changes incorporating previous margins. The direct policy effect measures changes in household welfare when commuters change travel mode in response to increasing commuting costs, holding housing prices, traffic speed and residential locations fixed. The partial speed effect allows the driving speeds to adjust one-time from via equation 13, but does not impose the transportation sector's clearing condition. The third bar additionally incorporates the full equilibrium speed effect and additional changes in welfare when traffic speeds adjust further to clear the transportation sector. The last bar includes household sorting in addition to the three channels above. The welfare calculations account for subway costs (both construction and operating costs) and toll revenues (net of capital and operating costs for the congesting pricing system).

Figure 8: Optimal Congestion Pricing under the 2014 Subway Network

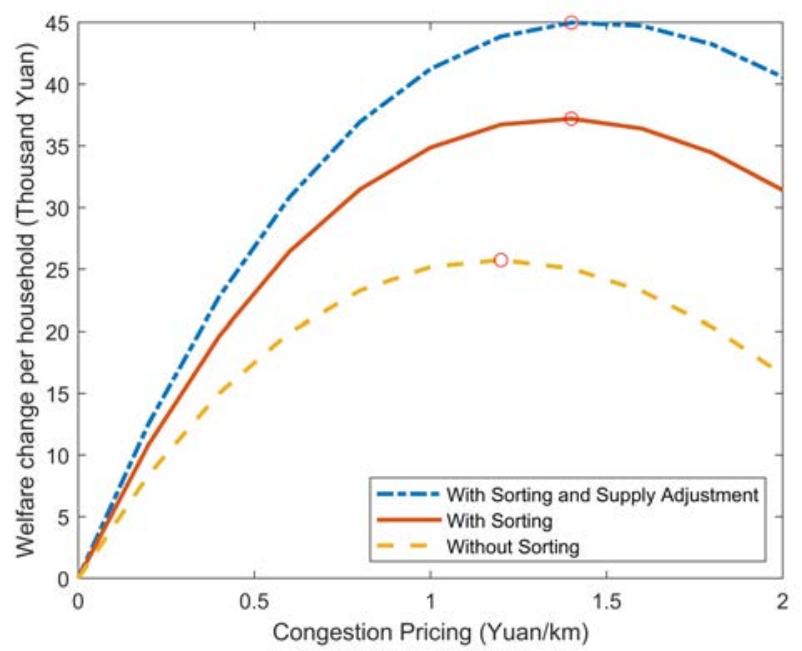

Note: The figure plots welfare changes against different congestion prices under the 2014 subway network, without household sorting (yellow dotted line), with sorting (orange solid line), and sorting together with housing supply adjustments (blue dashed line). The optimal congestion pricing is $¥ 1.2 / \mathrm{km}$ without sorting and $¥ 1.4 / \mathrm{km}$ with sorting. Sorting increases consumer welfare by $20 \%-30 \%$ and supply adjustment contributes to another $10 \%-20 \%$ for most congestion pricing levels. 
Table 1: Summary Statistics of Household Travel Survey

\begin{tabular}{lcccccc}
\hline & & 2010 & & \multicolumn{3}{c}{2014} \\
& $\mathrm{~N}$ & Mean & SD & N & Mean & SD \\
\hline Respondent characteristics & & & & & & \\
Income: $<¥$ 50k & 14780 & 0.48 & 0.50 & 20573 & 0.18 & 0.38 \\
Income: [¥ 50k, ¥ 100k) & 14780 & 0.39 & 0.49 & 20573 & 0.44 & 0.50 \\
Income: >=¥ 100k & 14780 & 0.13 & 0.34 & 20573 & 0.38 & 0.49 \\
Having a car (=1) & 14780 & 0.44 & 0.50 & 20573 & 0.62 & 0.49 \\
Female (=1) & 14780 & 0.44 & 0.50 & 20573 & 0.43 & 0.50 \\
Age (in years) & 14780 & 37.59 & 10.28 & 20573 & 38.47 & 9.84 \\
College or higher (=1) & 14780 & 0.61 & 0.49 & 20573 & 0.64 & 0.48 \\
Home within 4th ring (=1) & 14780 & 0.51 & 0.50 & 20573 & 0.41 & 0.49 \\
Workplace within 4th ring (=1) & 14780 & 0.59 & 0.49 & 20573 & 0.50 & 0.50 \\
Trip related variables & & & & & & \\
Travel time (hour) & 30334 & 0.87 & 1.06 & 42820 & 0.74 & 0.98 \\
Travel cost (¥) & 30334 & 2.47 & 5.55 & 42820 & 3.83 & 6.96 \\
Distance: $<2 \mathrm{~km}$ & 30334 & 0.25 & 0.43 & 42820 & 0.24 & 0.43 \\
Distance: [2, 5km) & 30334 & 0.27 & 0.45 & 42820 & 0.26 & 0.44 \\
\hline
\end{tabular}

Note: The table reports survey respondent demographics and trip attributes of all work commuting trips within the 6th ring road from the 2010 and 2014 Beijing Household Travel Survey. Travel time and travel cost are constructed as in Appendix A.1. Trip distance is measured by straight-lines. Distance $<2 \mathrm{~km}$ and Distance within $2-5 \mathrm{~km}$ flag commuting trips with a short to medium-distance.

Table 2: Summary Statistics of Housing Data

\begin{tabular}{lcccc}
\hline & Mean & SD & Min & Max \\
\hline Housing attributes & & & & \\
Transaction year & 2011 & 1.89 & 2006 & 2014 \\
Price $\left(¥ 1000 / \mathrm{m}^{2}\right)$ & 19.83 & 9.56 & 5.00 & 68.18 \\
Unit size $\left(\mathrm{m}^{2}\right)$ & 92.68 & 40.13 & 16.71 & 400.04 \\
Household annual income (¥1000) & 159.71 & 103.34 & 6.24 & 2556.90 \\
Primary borrower age & 33.99 & 6.62 & 20.00 & 62.00 \\
Housing complex attributes & & & & \\
Distance to key school $(\mathrm{km})$ & 6.05 & 5.61 & 0.03 & 23.59 \\
Complex vintage & 2004 & 8 & 1952 & 2017 \\
Green space ratio & 0.32 & 0.06 & 0.03 & 0.85 \\
Floor area ratio & 2.56 & 1.12 & 0.14 & 16.00 \\
Num. of units & 1972 & 1521 & 24 & 13031 \\
Home-work travel variables & & & & \\
Walking distance $(\mathrm{km})$ & 14.10 & 9.51 & 0.00 & 62.92 \\
Driving distance $(\mathrm{km})$ & 16.13 & 10.87 & 0.00 & 85.22 \\
Home to subway distance $(\mathrm{km})$ & 2.13 & 2.31 & 0.04 & 28.37 \\
Subway route distance $(\mathrm{km})$ & 15.17 & 10.70 & 0.00 & 68.40 \\
\hline
\end{tabular}

Note: This table reports statistics from the 2006-2014 mortgage dataset. The number of housing transactions is 79,884 , all of which are within the 6th ring road. The dataset is weighted to match the population of all home sales. A housing complex consists of a group of buildings in the same development. Distance to key school is the distance to the nearest signature elementary school. Home to subway distance is the distance to the nearest subway station. Subway route distance is the distance between the two subway stations that are closest to home and work locations. 
Table 3: Estimation Results for Travel Mode Choices

\begin{tabular}{|c|c|c|c|c|c|c|}
\hline & \multicolumn{3}{|c|}{ Logit } & \multicolumn{3}{|c|}{ Random coefficient } \\
\hline & (1) & (2) & (3) & (4) & (5) & (6) \\
\hline Travel time $\left(\gamma_{1}\right)$ & $\begin{array}{l}-1.194 \\
(0.082)\end{array}$ & $\begin{array}{c}-0.270 \\
(0.006)\end{array}$ & $\begin{array}{l}-0.191 \\
(0.006)\end{array}$ & & & \\
\hline Travel cost/hourly wage $\left(\gamma_{2}\right)$ & $\begin{array}{c}-1.578 \\
(0.324)\end{array}$ & $\begin{array}{c}-0.788 \\
(0.028)\end{array}$ & $\begin{array}{l}-0.565 \\
(0.034)\end{array}$ & $\begin{array}{l}-1.411 \\
(0.041)\end{array}$ & $\begin{array}{l}-1.424 \\
(0.052)\end{array}$ & $\begin{array}{l}-2.531 \\
(0.065)\end{array}$ \\
\hline \multicolumn{7}{|c|}{ Random coefficients on travel time $\left(\mu_{\gamma}\right)$} \\
\hline Travel Time & & & & $\begin{array}{l}-0.955 \\
(0.008)\end{array}$ & $\begin{array}{l}-0.885 \\
(0.008)\end{array}$ & $\begin{array}{l}-0.931 \\
(0.012)\end{array}$ \\
\hline \multicolumn{7}{|c|}{ Random coefficients on mode dummies $\left(\sigma_{m}\right)$} \\
\hline Driving & & & & & $\begin{array}{c}3.394 \\
(0.049)\end{array}$ & $\begin{array}{c}3.391 \\
(0.054)\end{array}$ \\
\hline Subway & & & & & & $\begin{array}{c}4.470 \\
(0.142)\end{array}$ \\
\hline Bus & & & & & & $\begin{array}{c}3.851 \\
(0.056)\end{array}$ \\
\hline Bike & & & & & & $\begin{array}{c}3.887 \\
(0.054)\end{array}$ \\
\hline Taxi & & & & & & $\begin{array}{c}4.203 \\
(0.353)\end{array}$ \\
\hline Mode * year FE & Yes & Yes & Yes & Yes & Yes & Yes \\
\hline Mode $*$ trip related FE & & Yes & Yes & Yes & Yes & Yes \\
\hline Mode $*$ demographic FE & & & Yes & Yes & Yes & Yes \\
\hline Log-likelihood & $-116,287$ & $-109,929$ & $-91,119$ & $-87,353$ & $-85,099$ & $-77,706$ \\
\hline Implied mean VOT & 0.757 & 0.342 & 0.339 & 1.760 & 1.615 & 0.956 \\
\hline Implied median VOT & 0.757 & 0.342 & 0.339 & 1.557 & 1.429 & 0.846 \\
\hline
\end{tabular}

Note: The number of observations are 73,154 . The specifications include an increasingly rich set of fixed effects interacting with travel model dummies. Trip related FE includes trip distance bins and ring road dummies for the origin and destination (e.g., if the origin is between the 2nd and 3rd ring roads). Demographics FE includes a respondent's age, gender, education, and car ownership. The first three specifications are multinomial logit while the last three add random coefficients. The distribution of preference on travel time is specified as a chi-square distribution (winsorized at the 5th and 95th percentile) with three degrees of freedom to allow for long tails. The estimates of $\mu_{\gamma}$ are provided in the table. The random coefficients on travel mode dummies (driving, subway, bus, bike, and taxi) are assumed to have a normal distribution with a standard deviation of $\sigma_{m}$. The last two rows report the implied mean and median value of time (VOT). Standard errors are displayed below parameter estimates. 
Table 4: Housing Demand - Nonlinear Parameters from Simulated MLE

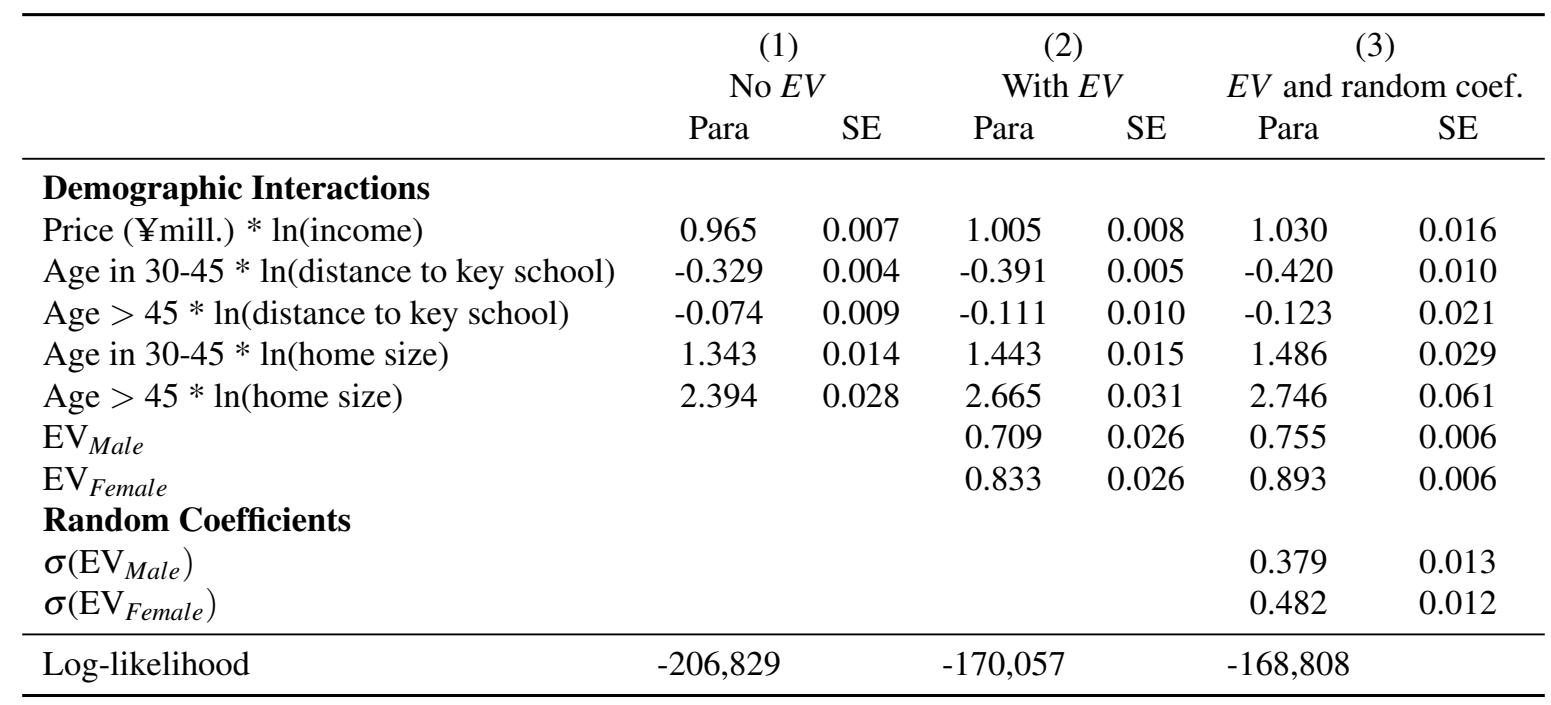

Note: this table reports MLE estimates of housing demand's nonlinear parameters using mortgage data from 2006-2014 with 77,696 observations. The ease-of-commuting utility $(E V)$ is constructed using Column 6 of Table 3 via equation (5). The first specification does not include $E V$, the second specification does, and the third specification further incorporates random coefficients the on $E V$ terms.

Table 5: Housing Demand - Linear Parameters

\begin{tabular}{lcccccc}
\hline & OLS & OLS & IV1 & IV2 & IV2+IV3 & All IVs \\
& $(1)$ & $(2)$ & $(3)$ & $(4)$ & $(5)$ & $(6)$ \\
\hline Price (¥mill.) & -2.240 & -2.191 & -7.091 & -6.283 & -6.454 & -6.596 \\
& $(0.186)$ & $(0.184)$ & $(1.640)$ & $(0.867)$ & $(0.583)$ & $(0.534)$ \\
Ln(home size) & -3.648 & -3.797 & 4.721 & 3.331 & 3.631 & 3.879 \\
& $(0.257)$ & $(0.261)$ & $(2.927)$ & $(1.505)$ & $(1.022)$ & $(0.969)$ \\
Building age & -0.043 & -0.029 & -0.144 & -0.125 & -0.129 & -0.132 \\
& $(0.007)$ & $(0.006)$ & $(0.040)$ & $(0.020)$ & $(0.014)$ & $(0.013)$ \\
Floor area ratio & -0.006 & -0.009 & -0.019 & -0.023 & -0.023 & -0.023 \\
& $(0.034)$ & $(0.025)$ & $(0.036)$ & $(0.032)$ & $(0.033)$ & $(0.034)$ \\
Ln(dist. to park) & 0.210 & 0.074 & -0.475 & -0.389 & -0.408 & -0.424 \\
& $(0.069)$ & $(0.057)$ & $(0.222)$ & $(0.117)$ & $(0.101)$ & $(0.103)$ \\
Ln(dist. to key school) & 0.950 & 0.782 & 0.210 & 0.323 & 0.304 & 0.288 \\
& $(0.080)$ & $(0.137)$ & $(0.213)$ & $(0.139)$ & $(0.121)$ & $(0.118)$ \\
\hline Year-Month-District FE & $\mathrm{Y}$ & $\mathrm{Y}$ & $\mathrm{Y}$ & $\mathrm{Y}$ & $\mathrm{Y}$ & $\mathrm{Y}$ \\
Neighborhood FE & & $\mathrm{Y}$ & $\mathrm{Y}$ & $\mathrm{Y}$ & $\mathrm{Y}$ & $\mathrm{Y}$ \\
\hline & & & & & & \\
First-stage Kleinberg-Paap F & & & 9.9 & 10.5 & 14.2 & 14.2 \\
Avg. Housing Demand Price elasticity & 2.96 & 2.96 & -1.94 & -1.04 & -1.34 & -1.44 \\
\hline
\end{tabular}

Note: The number of observations is 77,696. The dependent variable is the population-average utilities recovered using parameter estimates in Column (3) of Table 4). The first two columns are OLS estimates and the last four are IV estimates. The floor area ratio of a residential complex is total floor area over the complex's parcel size and measures complex density. Distance to key school is the distance to the nearest key elementary school. Column (3) use IV1 as price instruments, i.e. the number of homes that are within $3 \mathrm{~km}$ from a given home, outside the same complex, and sold in a two-month window. Columns (4), (5), and (6) use IV2, i.e. the average attributes of these homes (building size, age, log distance to park, and log distance to key school). Column (5) also includes IV3, the interaction between IV2 and the winning odds of the licence lottery. The winning odds decreased from $9.4 \%$ in January 2011 to $0.7 \%$ by the end of 2014. Column (6) uses all IVs. Standard errors are clustered at the neighborhood level. 
Table 6: Simulation Results with Household Sorting

\begin{tabular}{|c|c|c|c|c|c|c|c|c|c|c|c|c|}
\hline \multirow[b]{5}{*}{ Income relative to the median } & \multicolumn{6}{|c|}{2008 Subway Network } & \multicolumn{6}{|c|}{2014 Subway Network } \\
\hline & \multirow{2}{*}{\multicolumn{2}{|c|}{$\begin{array}{c}(1) \\
\text { No Policy }\end{array}$}} & \multicolumn{2}{|c|}{$(2)$} & \multicolumn{2}{|c|}{ (3) } & \multicolumn{2}{|c|}{ (4) } & \multicolumn{2}{|c|}{$(5)$} & \multicolumn{2}{|c|}{ (6) } \\
\hline & & & \multicolumn{2}{|c|}{ Driving restriction } & \multicolumn{2}{|c|}{ Congestion pricing } & \multicolumn{2}{|c|}{ Subway Expansion } & \multicolumn{2}{|c|}{+ Driving restriction } & \\
\hline & \multirow[b]{2}{*}{ High } & \multirow[b]{2}{*}{ Low } & \multicolumn{2}{|c|}{$\Delta$ s from (1) } & \multicolumn{2}{|c|}{$\Delta \mathrm{s}$ from $(1)$} & \multicolumn{2}{|c|}{$\Delta \mathrm{s}$ from $(1)$} & \multicolumn{2}{|c|}{$\Delta \mathrm{s}$ from $(1)$} & \multicolumn{2}{|c|}{$\Delta \mathrm{s}$ from $(1)$} \\
\hline & & & High & Low & High & Low & High & Low & High & Low & High & Low \\
\hline \multicolumn{13}{|c|}{ Panel A: travel mode shares in percentage points and average speed } \\
\hline Drive & 41.65 & 21.44 & -7.17 & -3.40 & -3.48 & -5.39 & -2.14 & -1.66 & -8.52 & -4.62 & -5.20 & -6.40 \\
\hline Subway & 9.02 & 10.77 & 1.29 & 0.70 & 0.84 & 0.96 & 4.62 & 6.06 & 5.79 & 6.44 & 5.24 & 6.83 \\
\hline Bus & 22.44 & 30.47 & 1.78 & 0.60 & 0.57 & 1.24 & -1.54 & -2.53 & 0.31 & -1.57 & -0.76 & -1.03 \\
\hline Bike & 15.96 & 24.01 & 1.60 & 0.80 & 0.77 & 1.78 & -0.80 & -1.64 & 0.52 & -0.94 & -0.13 & -0.13 \\
\hline Taxi & 2.20 & 1.32 & 1.19 & 0.55 & 0.63 & 0.57 & -0.16 & -0.11 & 0.89 & 0.36 & 0.39 & 0.36 \\
\hline Walk & 8.74 & 11.99 & 1.31 & 0.74 & 0.67 & 0.83 & 0.02 & -0.13 & 1.01 & 0.32 & 0.46 & 0.37 \\
\hline Speed $(\mathrm{km} / \mathrm{h})$ & \multicolumn{2}{|c|}{21.49} & \multicolumn{2}{|c|}{3.83} & \multicolumn{2}{|c|}{3.83} & \multicolumn{2}{|c|}{1.49} & \multicolumn{2}{|c|}{5.08} & \multicolumn{2}{|c|}{5.29} \\
\hline \multicolumn{13}{|l|}{ Panel B: sorting outcomes } \\
\hline Distance to work (km) & 18.56 & 15.66 & 0.01 & 0.01 & -0.17 & -0.06 & 0.36 & 0.18 & 0.41 & 0.17 & 0.15 & 0.12 \\
\hline Distance to subway $(\mathrm{km})$ & 5.33 & 4.30 & -0.03 & 0.03 & -0.03 & 0.03 & -4.14 & -3.44 & -4.14 & -3.44 & -4.14 & -3.44 \\
\hline \multicolumn{13}{|c|}{ Panel C: welfare changes per household (thousand $¥$ ) } \\
\hline Consumer surplus (+) & & & -227.1 & -32.7 & -98.2 & -73.1 & 220.3 & 100.0 & -14.0 & 64.0 & 108.7 & 28.7 \\
\hline Toll revenue $(+)$ & & & & & 137.4 & 137.4 & & & & & 127.7 & 127.7 \\
\hline Subway cost (-) & & & & & & & 103.0 & 103.0 & 103.0 & 103.0 & 103.0 & 103.0 \\
\hline Net welfare & & & -227.1 & -32.7 & 39.2 & 64.3 & 117.3 & -3.0 & -117.0 & -39.0 & 133.4 & 53.4 \\
\hline
\end{tabular}

Note: Simulations use the 2014 cohort (households who purchased homes in 2014) and are based on parameters reported in Column (6) of Table 3 , Column 3 of Table 4, and Column (6) of Table 5. Appendix E explains the simulation procedure. We incorporate household sorting and but keep housing supply fixed. Column (1) reports results when no policy was in place. Columns (2) to (6) present differences from Column (1). Driving restriction prohibits driving in one of five work days. Congestion pricing is set at $¥ 1.13$ per km to generate the same speed improvement as the driving restriction. High-income household are those with income above the median. Toll revenue, net of the capital and operating costs of the system, is recycled uniformly across households. Subway cost includes the construction and operation costs that are equally distributed among 7.2 million households. Net welfare is consumer surplus plus recycled revenue and minus subway costs. See Appendix Section E for more details. 
Table 7: Importance of Sorting and Endogenous Congestion and Various Extensions

\begin{tabular}{|c|c|c|c|c|c|c|c|c|c|}
\hline \multirow[b]{3}{*}{ Income relative to the median } & \multicolumn{3}{|c|}{ Driving restriction } & \multicolumn{3}{|c|}{ Congestion pricing } & \multicolumn{3}{|c|}{ Subway expansion } \\
\hline & \multirow{2}{*}{$\begin{array}{c}\Delta \text { Speed } \\
(\mathrm{km} / \mathrm{h})\end{array}$} & \multicolumn{2}{|c|}{$\Delta$ Welfare $(¥ 1,000)$} & \multirow{2}{*}{$\begin{array}{c}\Delta \text { Speed } \\
(\mathrm{km} / \mathrm{h})\end{array}$} & \multicolumn{2}{|c|}{$\Delta$ Welfare $(¥ 1,000)$} & \multirow{2}{*}{$\begin{array}{c}\Delta \text { Speed } \\
(\mathrm{km} / \mathrm{h})\end{array}$} & \multicolumn{2}{|c|}{$\Delta$ Welfare $(¥ 1,000)$} \\
\hline & & High & Low & & High & Low & & High & Low \\
\hline \multicolumn{10}{|c|}{ Panel (A): importance of sorting and endogenous congestion } \\
\hline With sorting (main results) & 3.83 & -227.1 & -32.7 & 3.83 & 39.2 & 64.3 & 1.49 & 117.3 & -3.0 \\
\hline Without sorting & 3.82 & -227.3 & -31.0 & 3.61 & 28.1 & 55.6 & 1.76 & 104.7 & 14.0 \\
\hline With sorting but without endogeneous congestion & 5.47 & -111.6 & -8.7 & 5.62 & 112.2 & 75.1 & 2.36 & 260.1 & 107.7 \\
\hline \multicolumn{10}{|l|}{ Panel (B): extensions and robustness checks } \\
\hline With housing supply & 3.83 & -226.9 & -31.6 & 3.97 & 51.4 & 65.7 & 1.13 & 84.4 & 2.3 \\
\hline With location-specific traffic density & 3.82 & -227.6 & -3.3 & 3.81 & 31.7 & 61.1 & 1.48 & 113.0 & -0.4 \\
\hline Without random coefficients & 4.59 & -1447.6 & -338.0 & 4.59 & -406.9 & -3.6 & 0.16 & 15.5 & -42.5 \\
\hline With migration & 4.65 & -197.7 & -26.9 & 4.63 & 72.7 & 71.3 & 0.73 & 80.3 & -10.2 \\
\hline With consumption access & 3.83 & -302.0 & -43.5 & 3.83 & 52.2 & 85.5 & 1.49 & 190.7 & 30.3 \\
\hline
\end{tabular}

Note: Panel (A) examines the importance of sorting and endogenous congestion. Each cell reports changes relative to the no-policy scenario. Speed without any policy is $21.49 \mathrm{~km} / \mathrm{h}$. The unit of welfare changes is $¥ 1,000$. Congestion pricing is fixed at $¥ 1.13$ per km. The first row summarizes results in Table 6 . "Without sorting" holds residential locations and does not impose the housing market clearing condition. "With sorting but without endogenous congestion" keeps sorting but shuts down endogenous congestion. To do so, we adjust traffic speed once in response to households' travel mode changes via equation (13), but do not impose the transportation sector's equilibrium condition. Panel (B) considers various extensions. "With housing supply" assumes that the housing supply responds to price changes under a constant price elasticity of 0.53. "With location-specific traffic density" incorporates ring road-band specific traffic densities and adjusts travel speeds using the corresponding density in appropriate ring road bands. "Without random coefficients" re-estimate the entire model with no random coefficients and repeat the counterfactual analysis. "With migration" assumes 5\% more vehicles (in-migration) under the subway congestion and 5\% fewer vehicles (out-migration) under the driving restriction and congestion pricing. "With consumption access" incorporates additional 33\% of changes in consumer surplus through the changing availability of consumption services (restaurants, shops, and theaters). 